\title{
التفيرات السياسية والاجتماعية وعلاقتها بمستوى الطموح \\ لدى الشباب وقدرته على إتخاذ القرار
}

اعداد

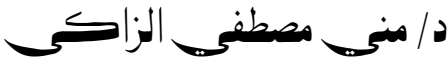

أستاذ مساعد ورئيس قسم إدارة المنزل كلية الاقتصاد المنزلي جامعة الأزهر

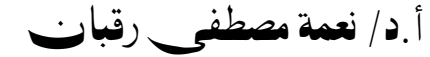

أستاذ ورئيس قسم إدارة المنزل والمؤسسات

كلية الاقتصاد المنزلي جامعة المنوفية

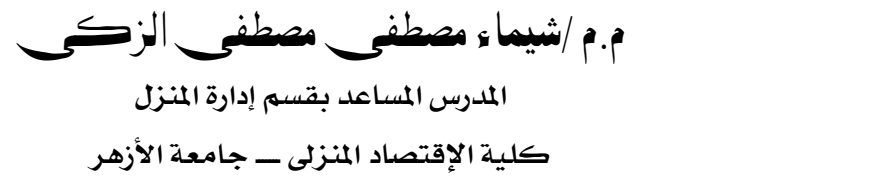

مجلة بحوث التربية النوعية ـ جامعة المنصورة

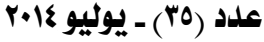




\section{التغيرات السياسية والاجتماعية وعلاقتها بمستوى الطموح \\ لدى الشباب وقدرته على إتخاذ القرار}

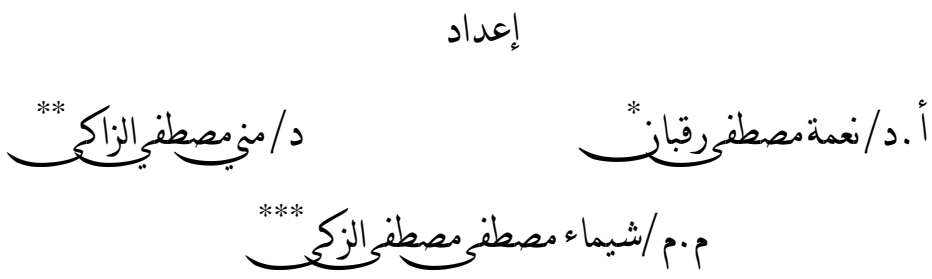

هلفص الدراسة

يهدف البحث بصفة رئيسية إلى دراسـة العلاقـة بـين التغيرات السياسية بأبعادهـا ( التنشئسة

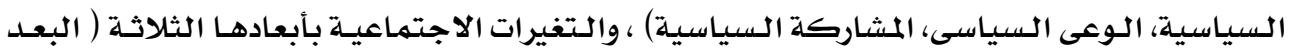

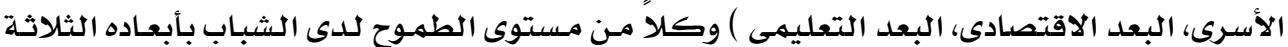

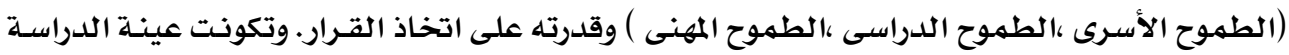

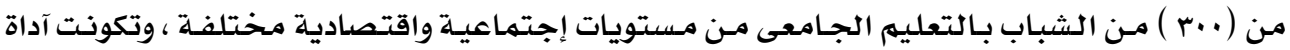

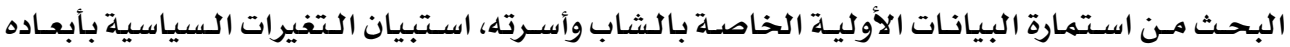

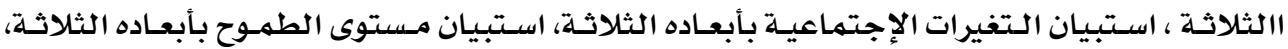
استبيان القدرة على إتخاذ القرار.

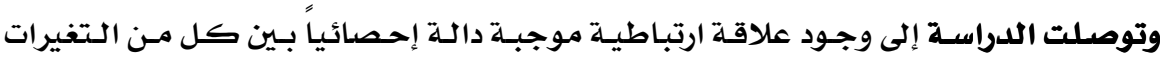

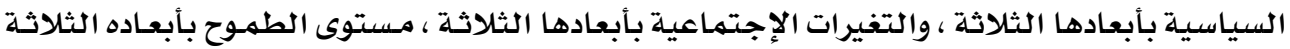

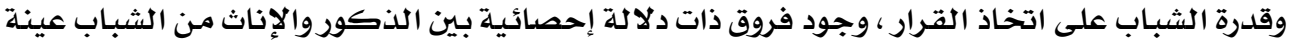

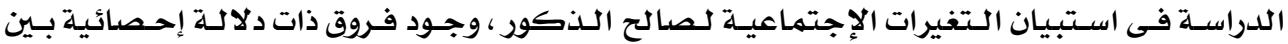

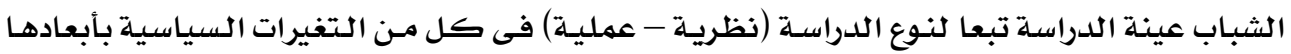

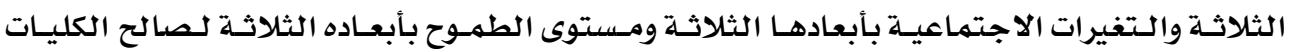

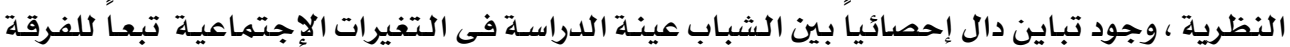

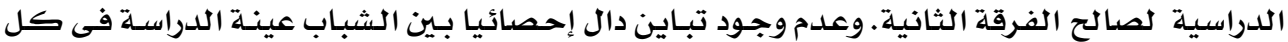

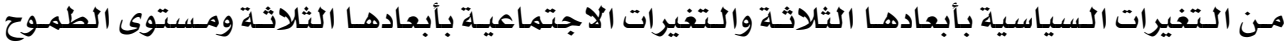

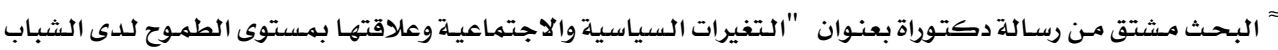

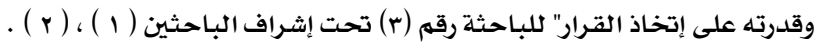

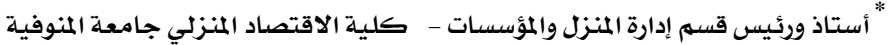

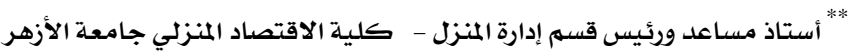

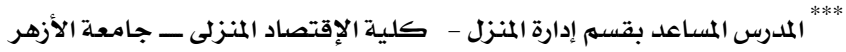


بأبعـاده الثلاثة واستبـيان القــرة على اتخـاذ القـرار تبعـاً لمستوى تعلـيهم الأب والأم وتبعـاً لفئـات الدخل الشهرى لنلأسـرة.

وأوصست الدراسـة بضرورة توفير مناخ أسري ودراسي مناسب للشبـاب يزيد من توجيه التغيرات

السيـاسيـة والاجتماعية الإيجابية من أجل رفع مستوي الطموح لديهم ، تفعيـل دور مؤسسـات التنشئسة

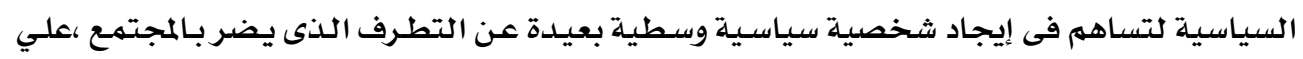

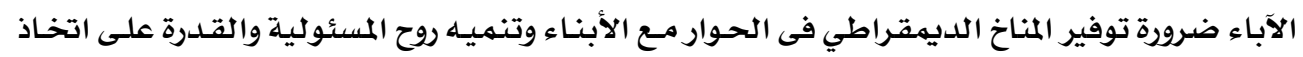

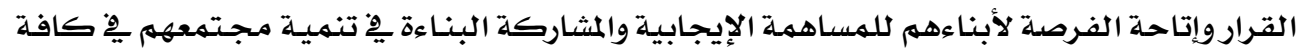
المجالات المجتمعية اقتصادية كانت أو سياسية أو إجتماعية ،إعادة صياغة فلسفة التعليهم الجـامعي و أهدافه بما يتلاءم مـع التطورات السياسية و الاقتصـادية والاجتهماعيـة الجـاريـة.

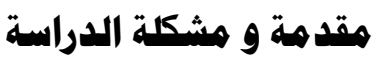

يعتـبر الـتغير واقـع حتهـى وحركة طبيعيـة متواصسلة لاسـبيل لايقافهـا أو منعها ، فـالكون برمته يخضع لتغيرات متواصلة عبر ملايـين السنـين ومجتمعـات اليوم تشهد تغـيرات كميـة وكيفيـة

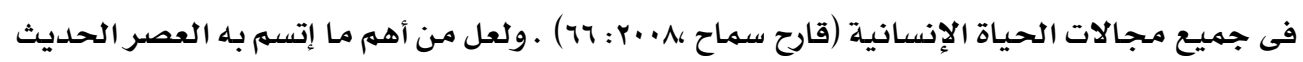

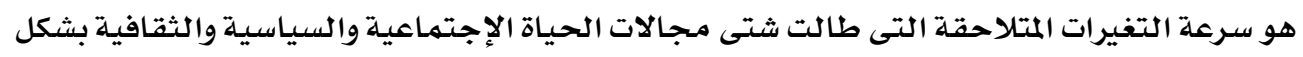

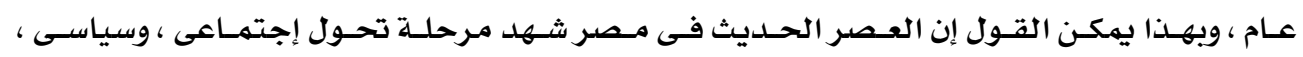

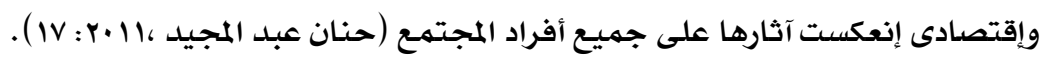

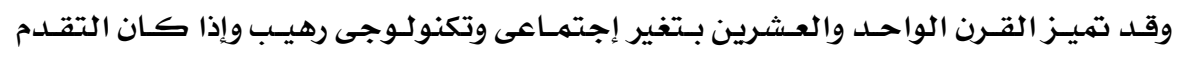

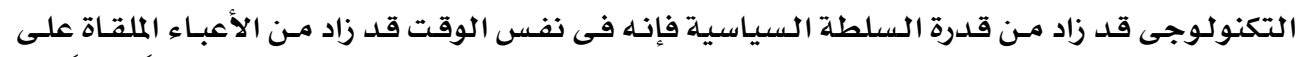

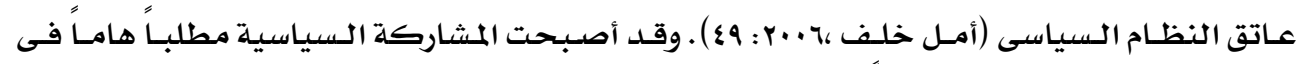

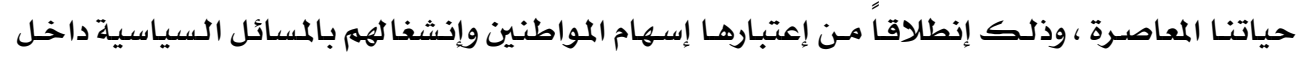

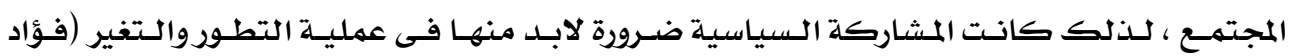

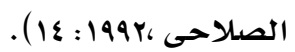

فالتغير الاجتماعى يشير إلى تحول اجتماعى فى المجال الثقافى والمؤسسى عبر الزمـن هـذا

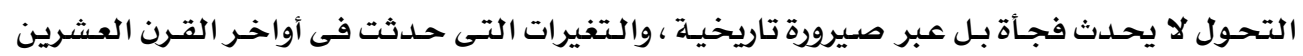

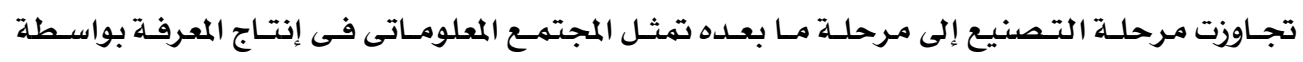

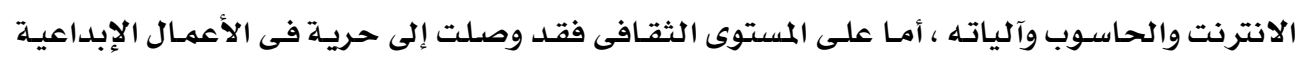

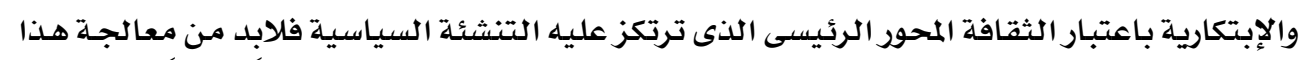

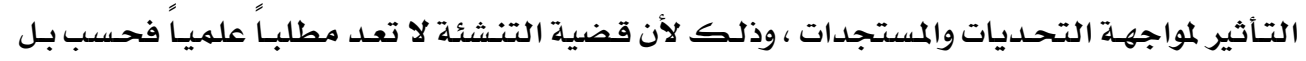
تمثل فى واقع الأمـر ضـرورة علمية يفرضها الواقع الاجتمهاعى والسياسى ذاته وتتطلبها عمليـة التتهيـة

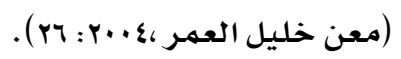

ونجـــد أن الثباب يحتـل مكانة هامة في مختلف المجتمعات الإنسانية وذلك من خلال دورهم فـى عملية التغير الاجتماعي و التحديث لمجتمعهم ، فضلح عـن إسهامهم في الإبداع و الابتكار و التجديد 
وفي مو اجهة القيم التقليدية ، وليس ثمة شك في أن الظروف المحلية و القومية والعالمية التـي يعيش فيها

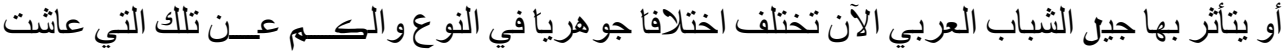

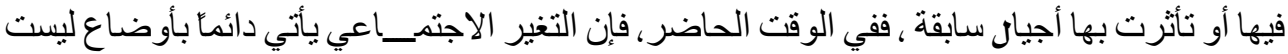

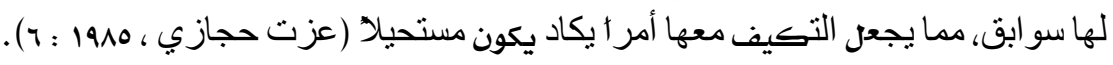

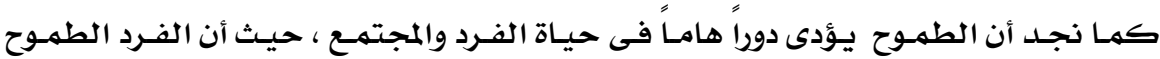

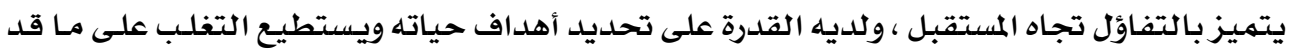

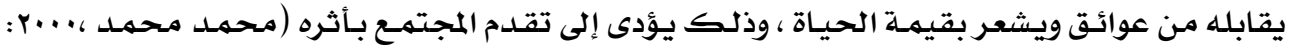

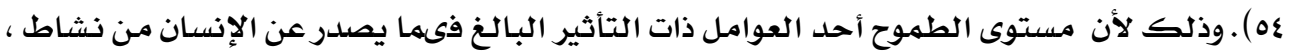

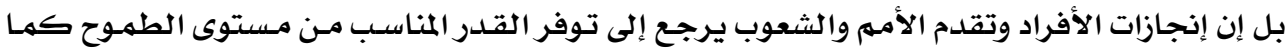

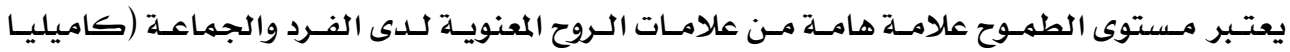

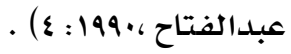

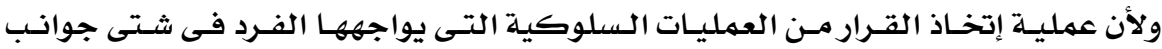

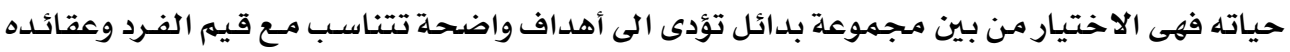

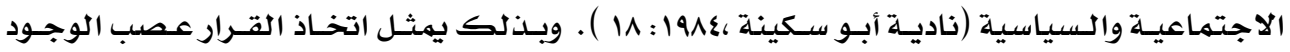

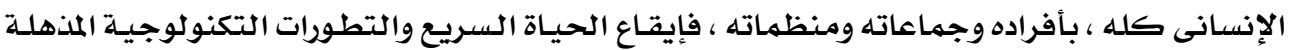

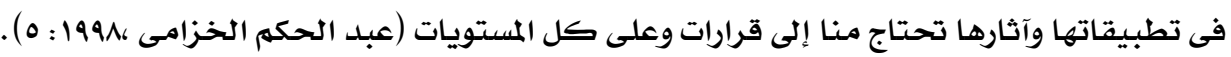

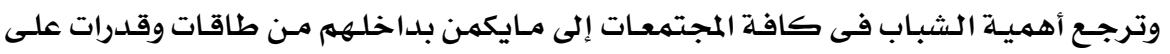

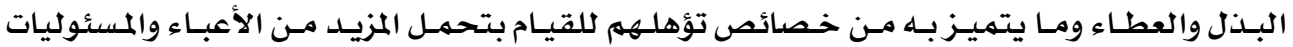

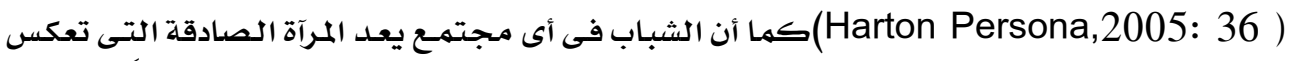

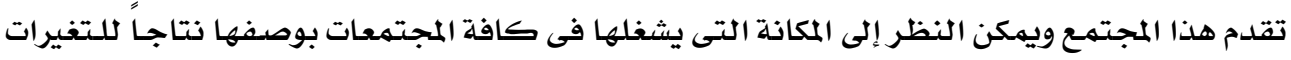

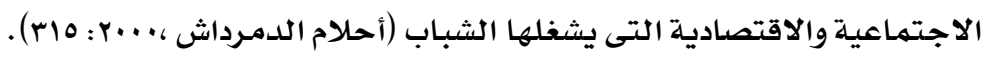

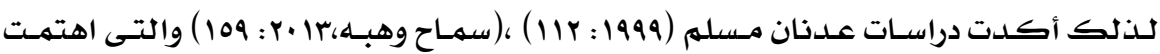

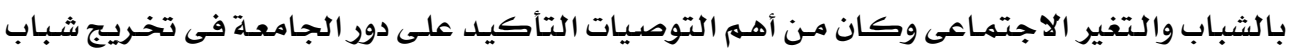

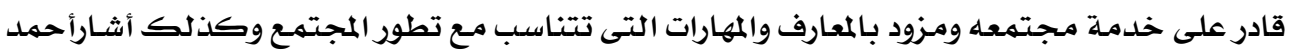

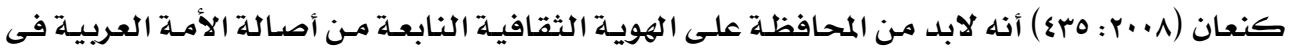

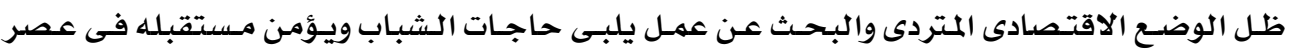

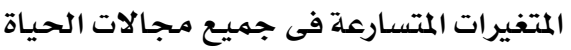
وقد شهـدت مصر فى السنوات الأخيرة تحـولات مهمـة فى أشكال المشاركة السياسية غير

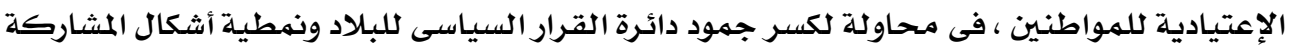

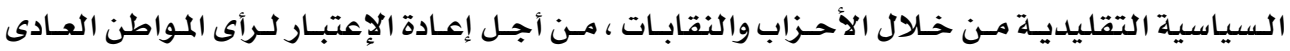

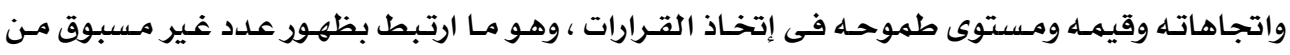

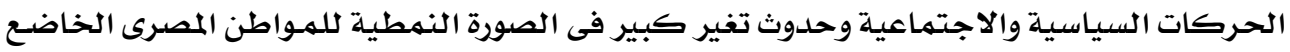




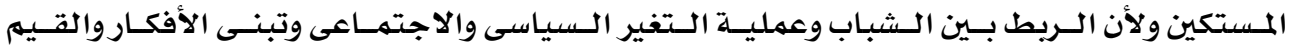

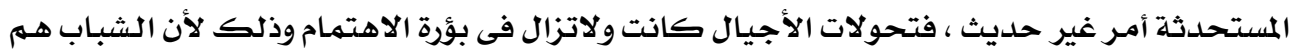

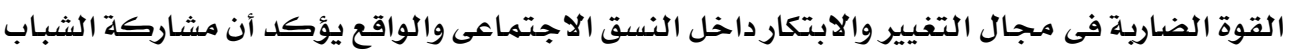

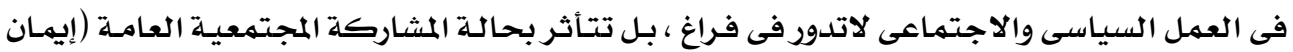

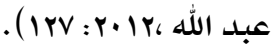

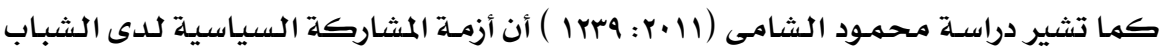

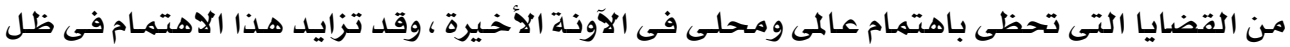

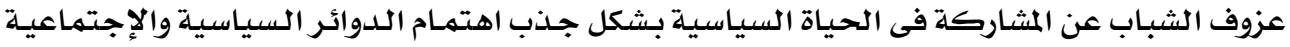

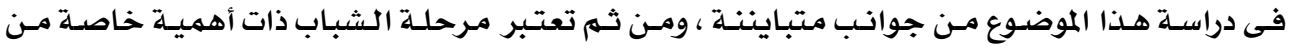

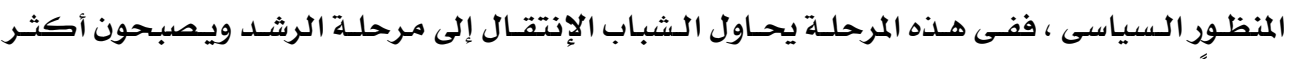

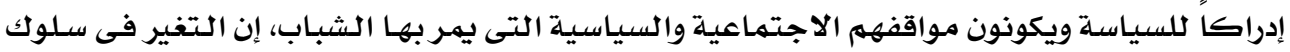

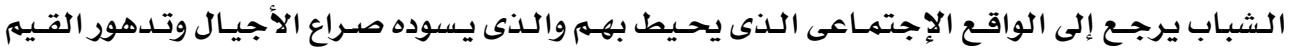

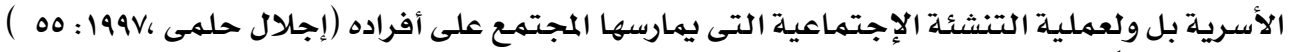

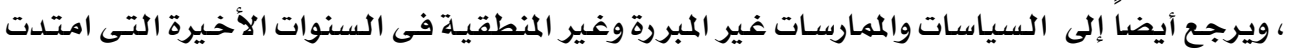

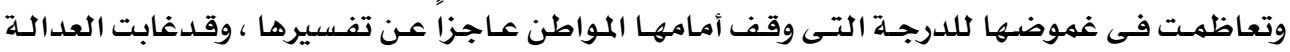

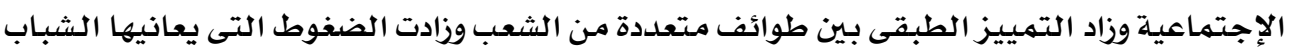

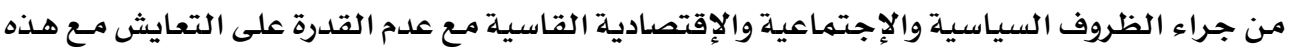

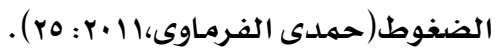

فمرحلة الشباب هى مـرحلـة التطلع إلى المستقبل بطموحسات عريضلة في إطـار مـن مثاليـات

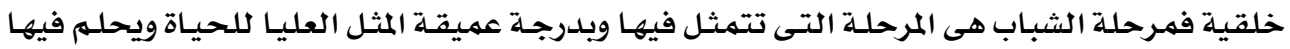

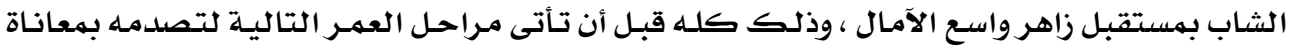

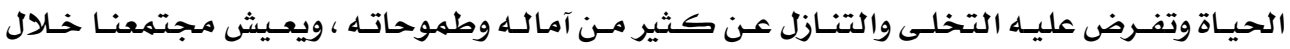

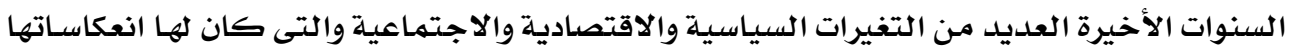

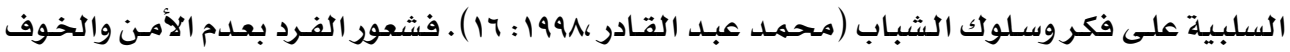

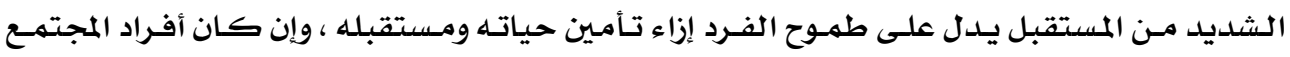

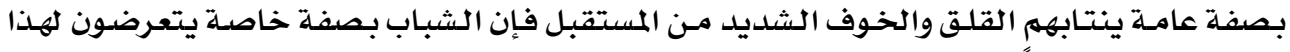

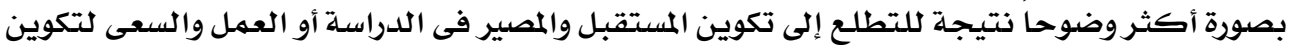

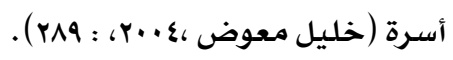

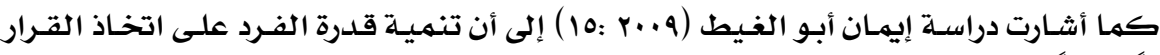

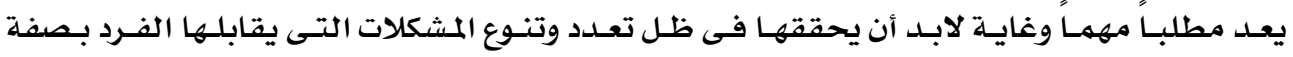

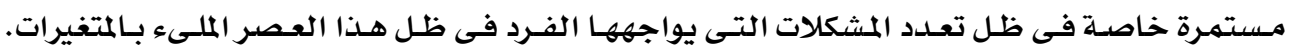

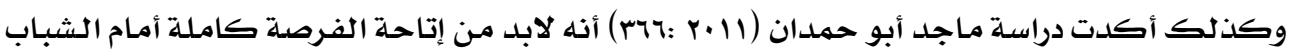


للمشاركة فى إتخاذ القرار داخل الأسرة الأمر الذى يهيئهم مستقبلاً للمساهمة الفعالة فى نشاطات

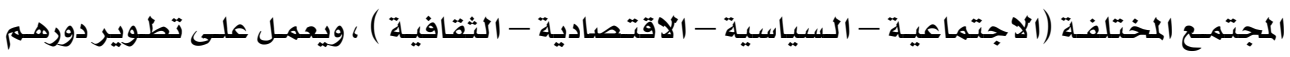

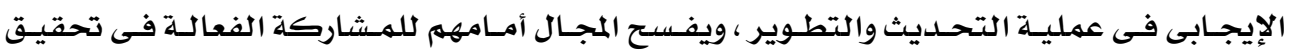

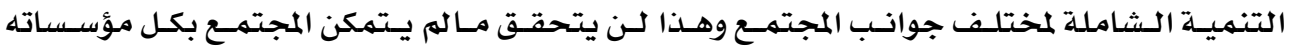

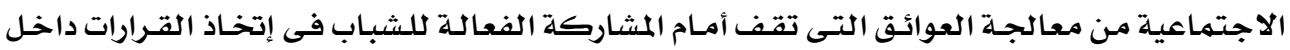
الأسرة وخارجها . الاجتهاعية من م.

\section{وفى ضوء ما سبق تتبلور مشكلة البحث الحالى فى التساؤل الآتى: ما العلاقة بين التغيرات}

السياسية والإجتماعية وكلاً من مستوى الطموح لدى الشباب وقدرته على إتخاذ القرار \&

\section{هدف الدراسة :}

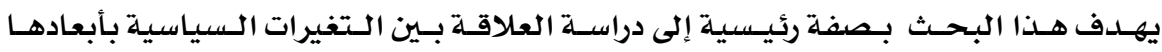

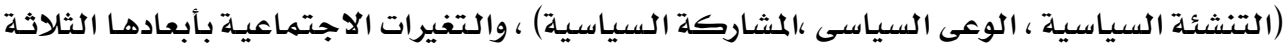

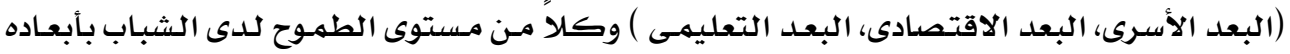

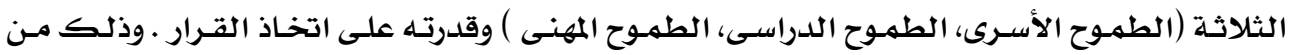
خلال عدة أهداف فرعية : ا- تحديد مستوى التغيرات السياسية والإجتماعية وكلاً من مستوى الطمـوح لدى الشبـاب وقدرتهـ على إتخاذ القرار

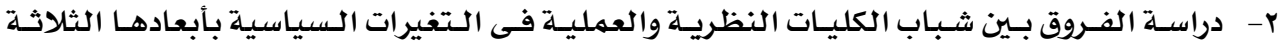

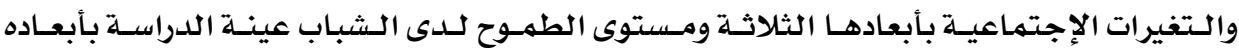
الثلاثة وقدرته على اتخاذ القرار

\section{أهمينة الدراسة الدكة}

ا- إثراء المكتبـة بأبحـاث متخصصدة في إدارة المنزل والمؤسسـات لها علاقـة وطيدة بالأحسداث الجاريـة

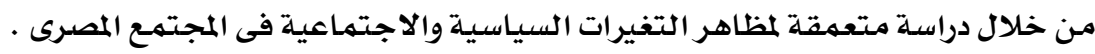

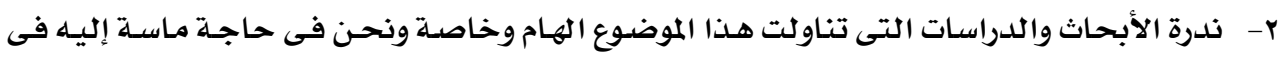
الفترة الراهنـة r- - توضيح الدـور الشمولى لمتخصص إدارة المنزل والمؤسسات فى المشاركة فى مثل هـذه الموضوعات

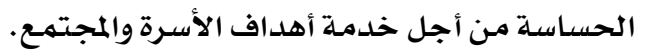

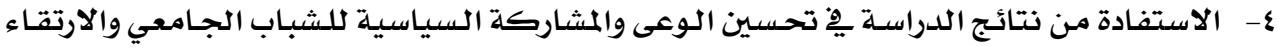

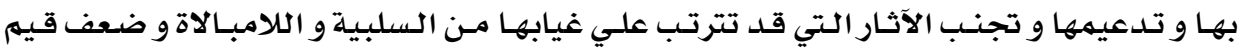

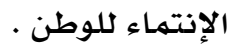




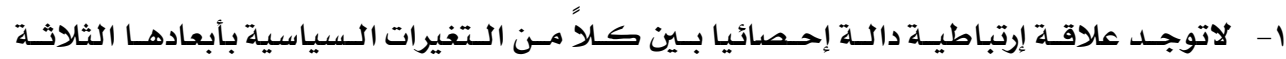

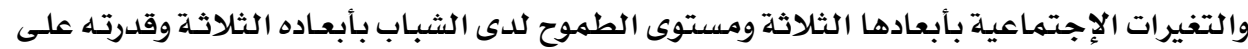
اتخاذ القرار • والتفيرات r- لا توجد فروق ذات دلالة إحصائية بـين شباب الكليـات النظريـة والعمليـة في التغيرات السياسية

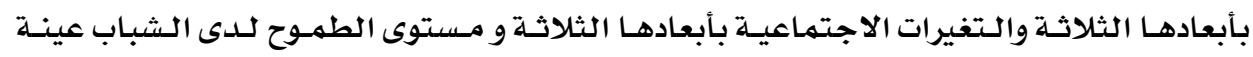

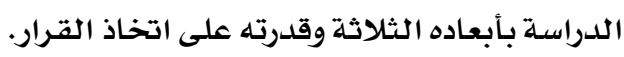

\section{الأسلوب البحثى للدراسة :}

أولاً : منهج الدراسة : تتبع الدراسة الحالية المنهج الوصفى التحليلى .

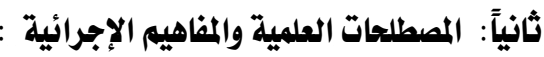

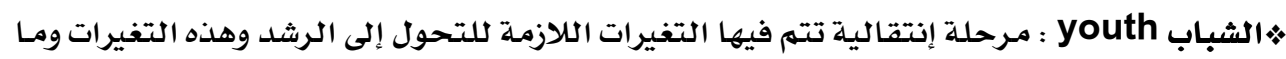

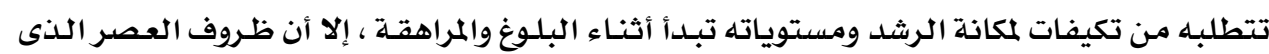

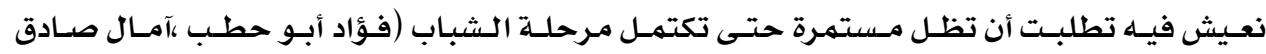
. (rrT: 1999،

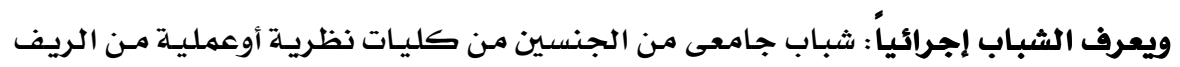

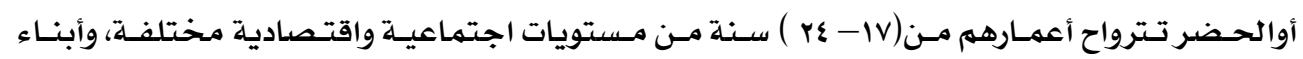

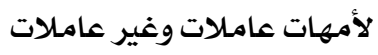
• التغيرات السياسية:Political changes : مجموعة التحولات التى تكسب الشباب مفاهيم

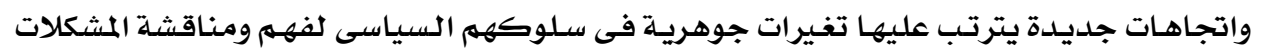

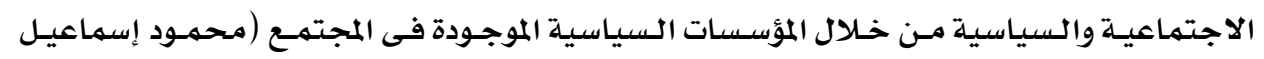
. (r): :199V،

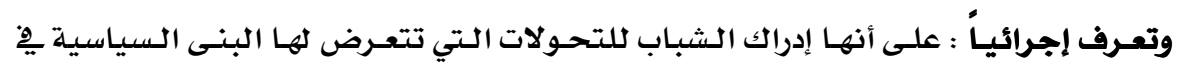

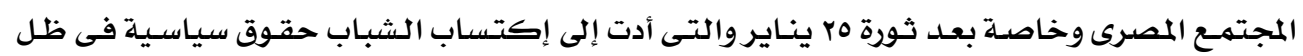

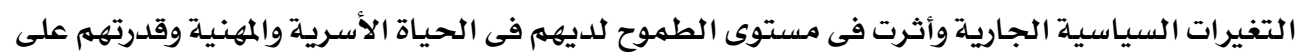
إتخاذ القرار.

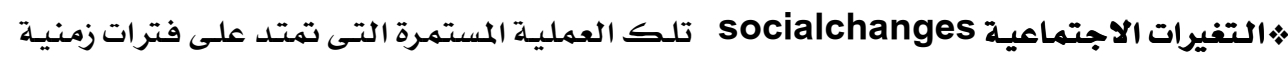

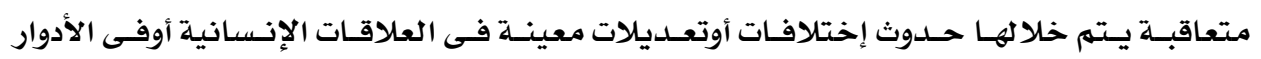

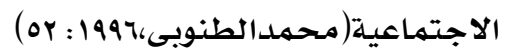

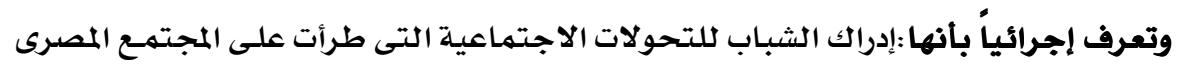

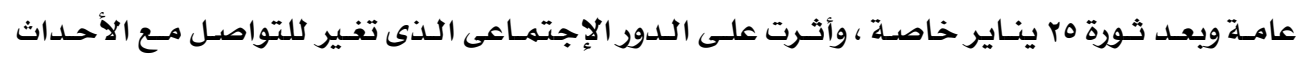




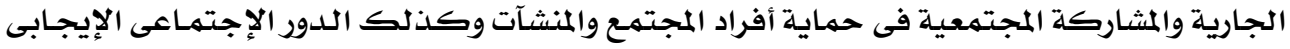

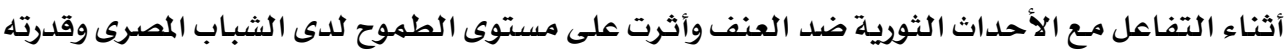

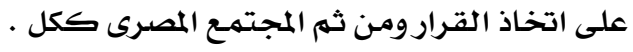

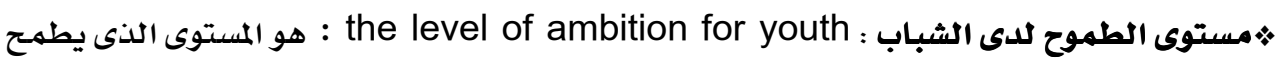

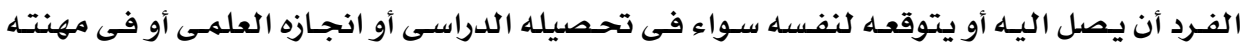

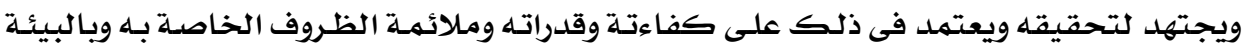

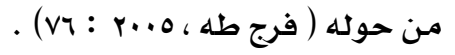

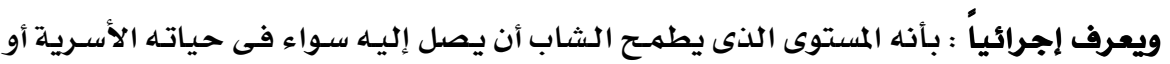

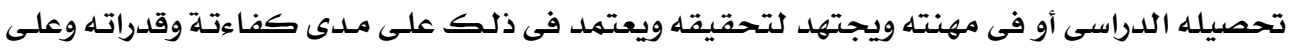

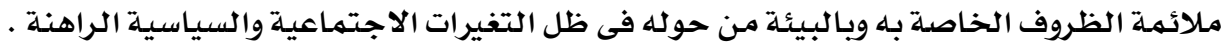

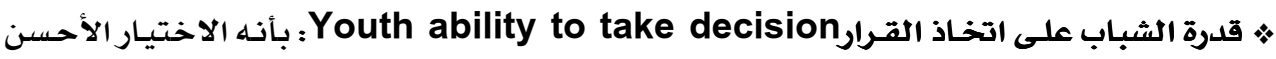

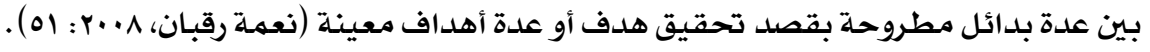

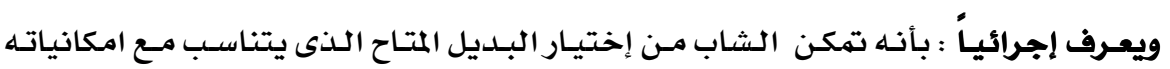

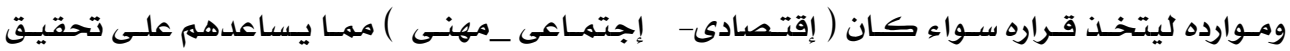

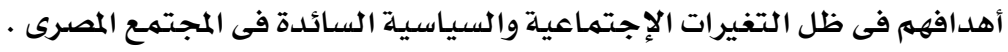

$$
\text { ثالثاً : حلدود الدراسة : }
$$

- الشاملة : تضمنت شاملة الدراسـة علي شباب المرحلة الجامعية لكليات نظرية وتطبيقية من سكان

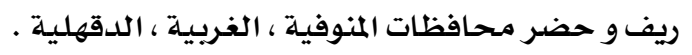

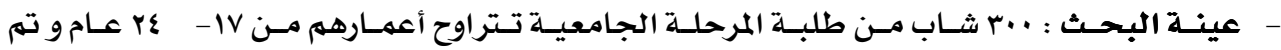

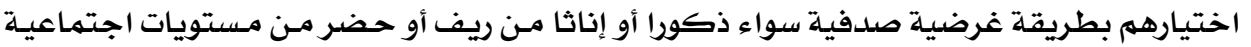

واقتصادية مختلفة.

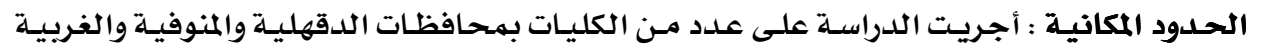

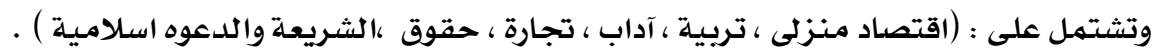

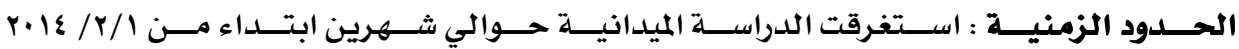

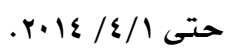

رابعاً : بناء و إعداد وتقنين أدوات الدراسة ( إعداد الباحثين ).

- استمارة البيانات العامة الخاصدة بشباب الجامعة وأسرهم ل

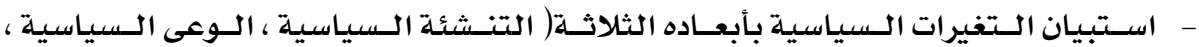

المشاركة السياسية).

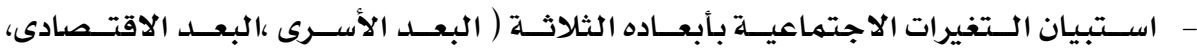

البعد التعليهى). 


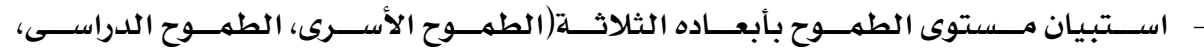

الطموح المهنى).

- - استبيان قدرة الشباب على اتخاذ القرار.

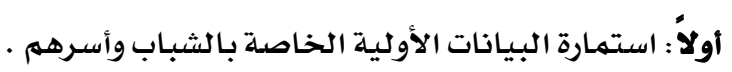

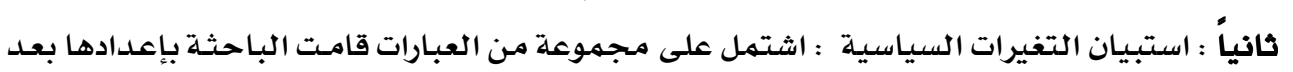

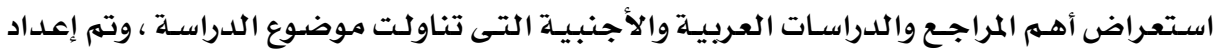

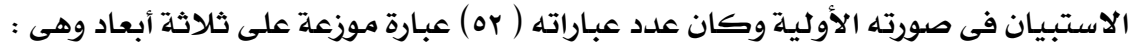

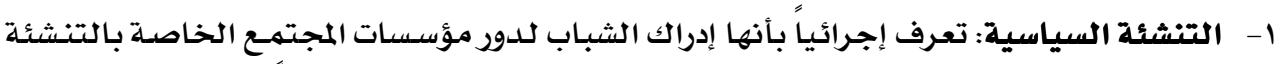

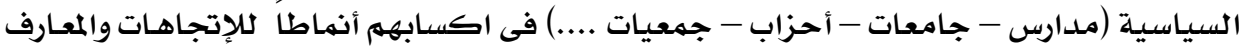

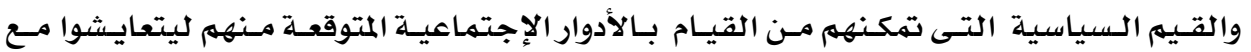

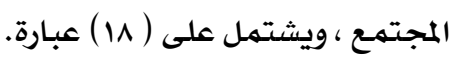

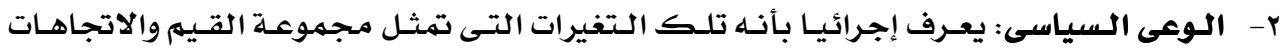

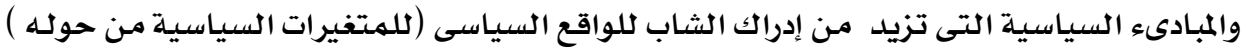

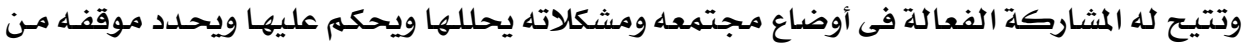

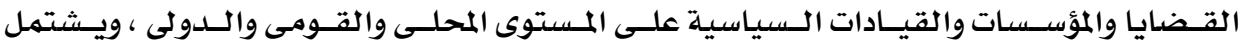
على (17) عبارة.

r- المشاركة السياسية: تعرف إجرائيا بأنها إدراك الشباب للتغيرات فى المشاركة الفعلية عامة وبعد

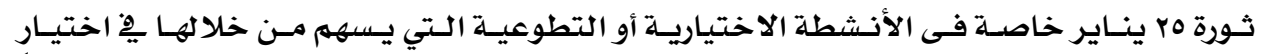

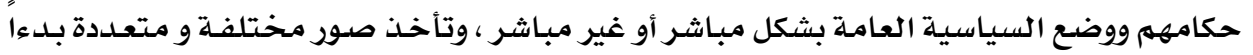

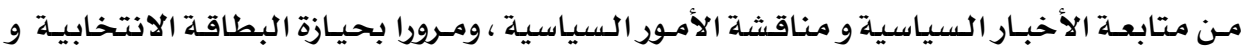

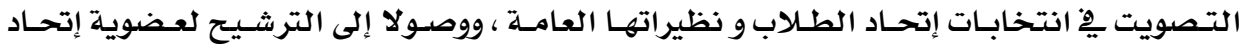

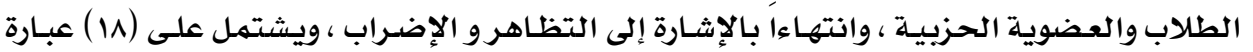

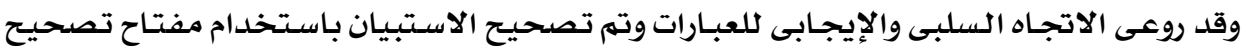

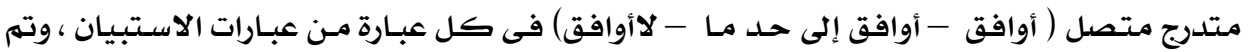

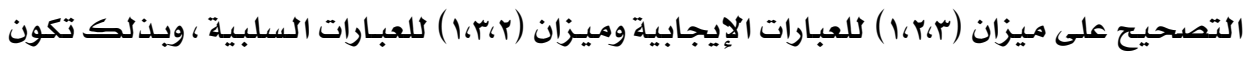

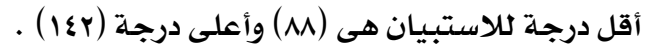

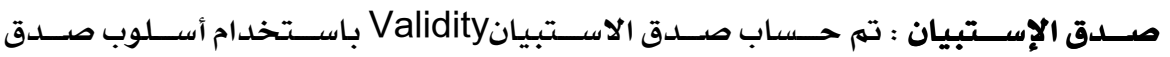

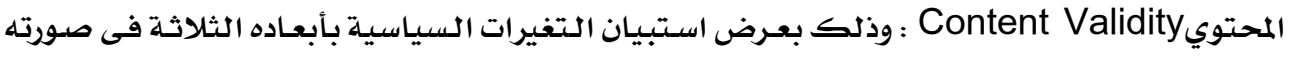

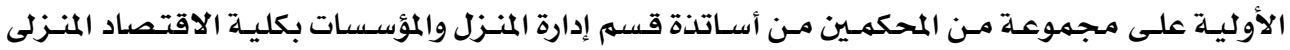

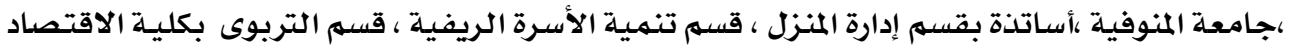

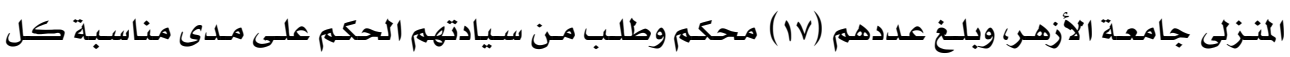

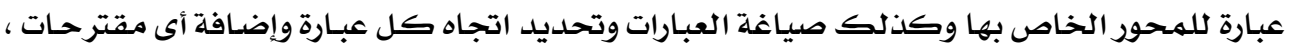




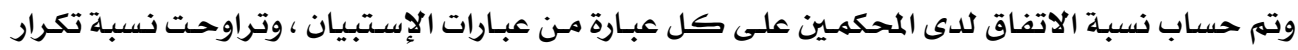

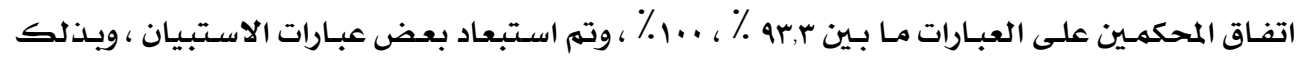

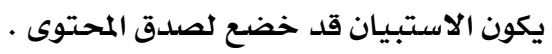

وقد تم قياس ثبات الاسـتبيان :- لحسـاب ثبـات الاستبيان تم التطبيق على عينـة قوامها

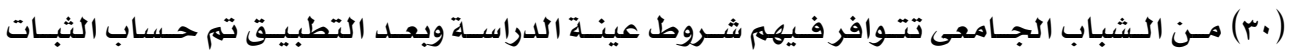

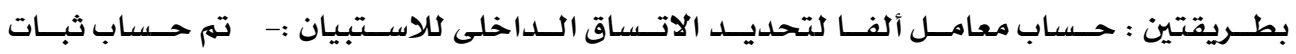

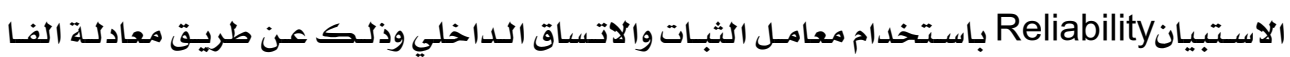

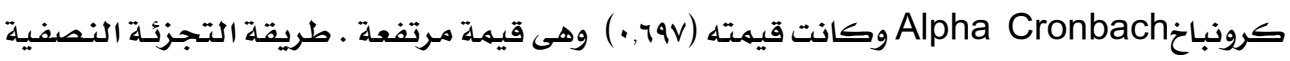
Split-Half

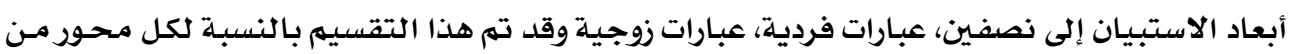

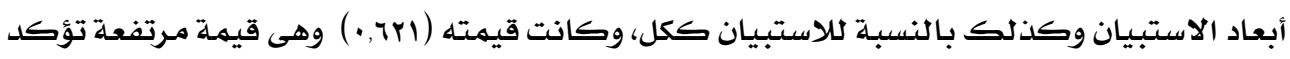

ثبات الآداة.

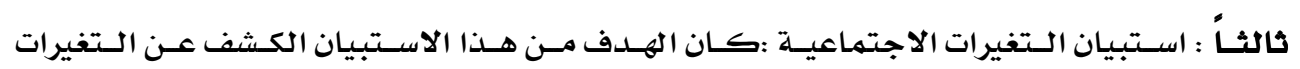

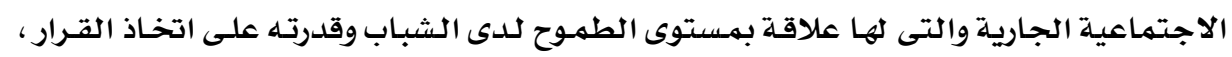

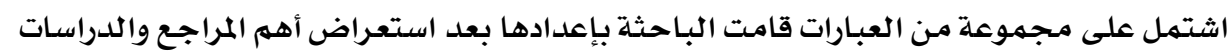

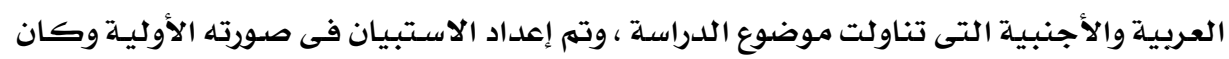
عدد عباراته ( rآ) عبارة موزعة على التئي ثلاثة أبعاد :

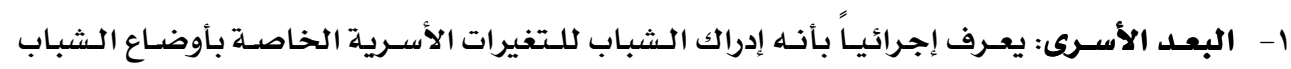

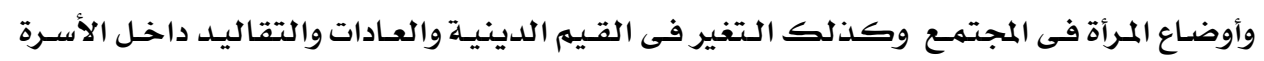

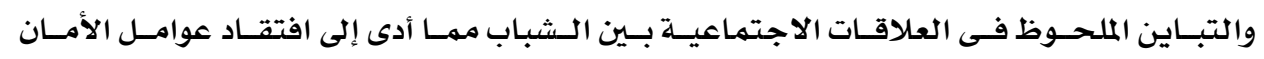
والاستقرار الاجتماعى واشتمل على ( المبـ ) عبارة.

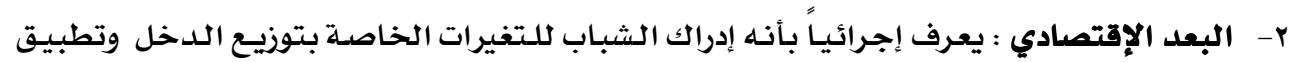

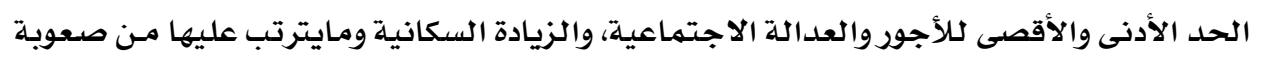

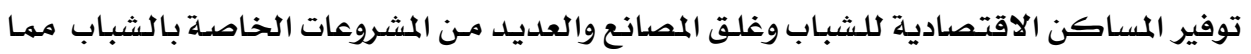

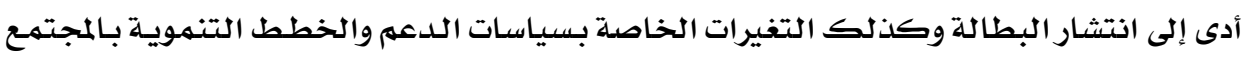

$$
\text { واشتمل على (r. أن ) عبارة. }
$$

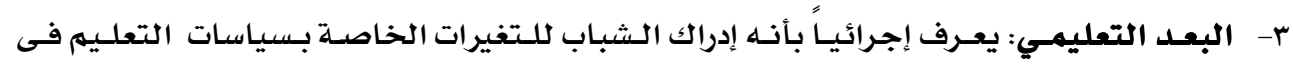

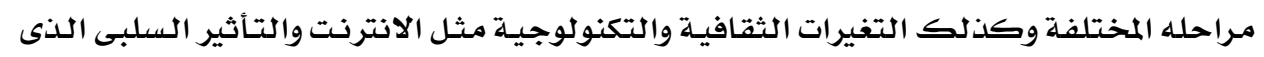

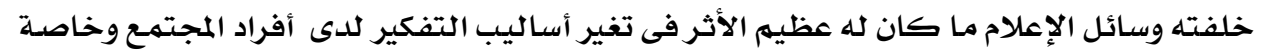

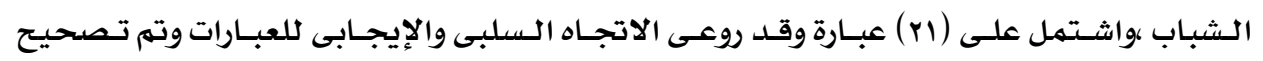

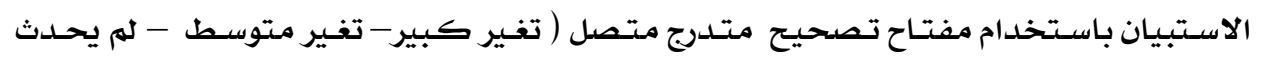




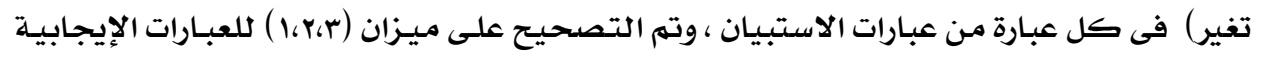

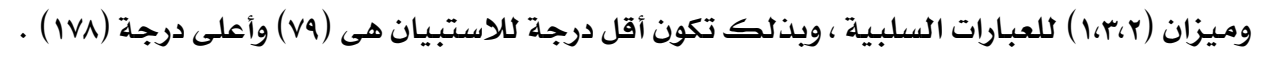

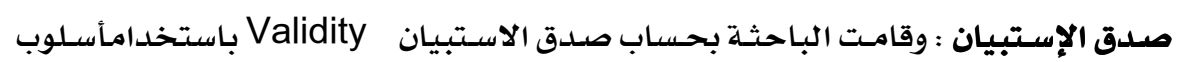

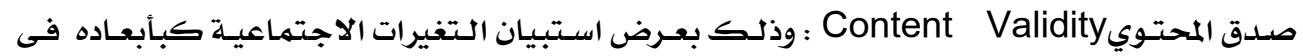

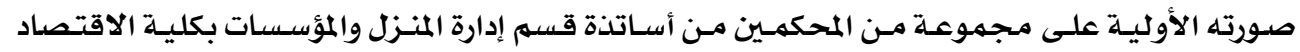

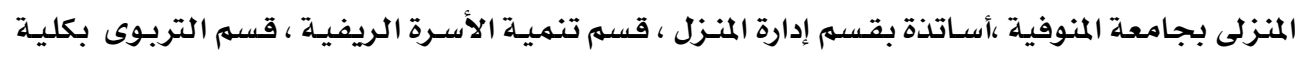

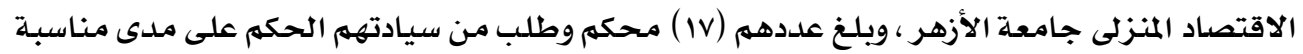

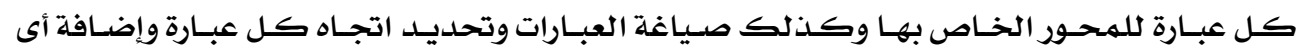

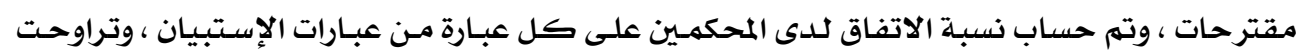

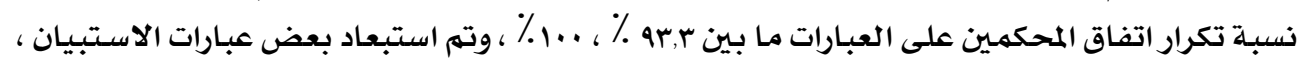

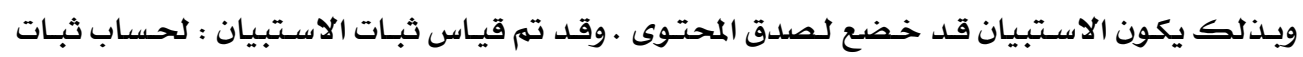

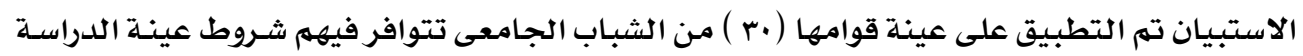

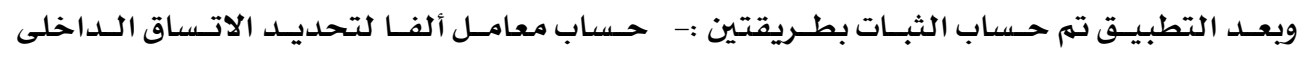

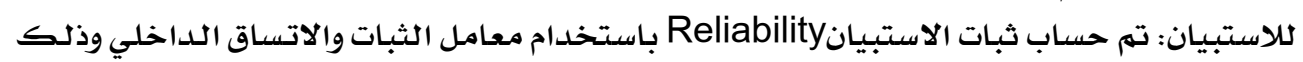

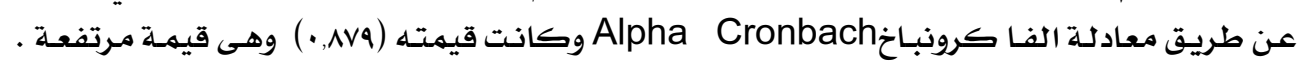

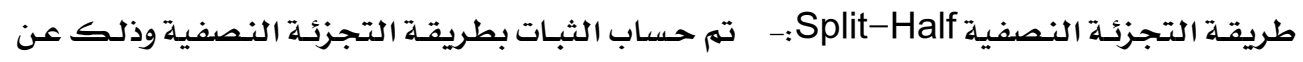

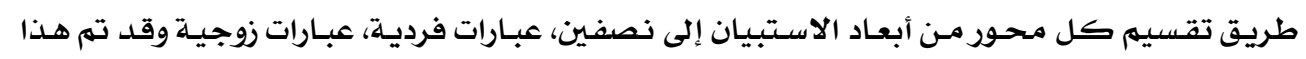

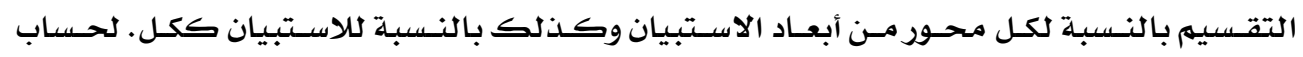

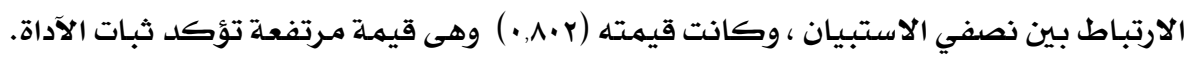

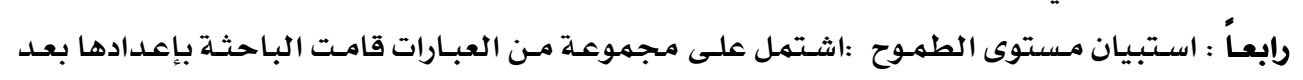

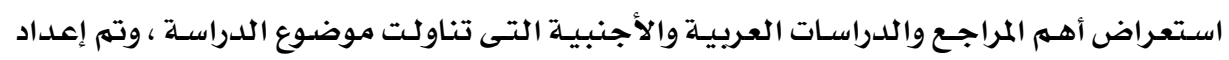

الاستبيان فى صورته الأولية وكان عدد عباراته (

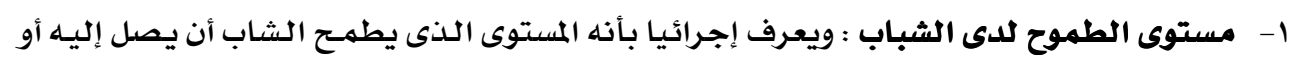

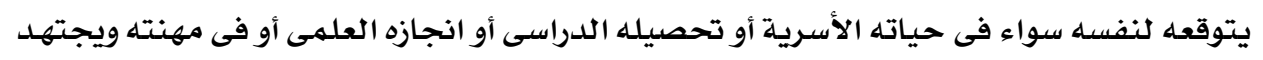

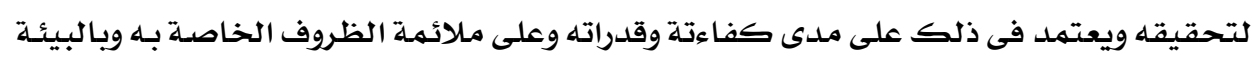

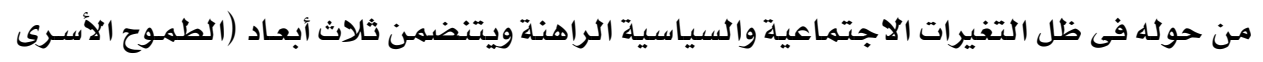

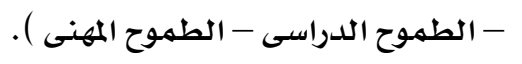

1- الطموح الأسرى: ويعرف إجرائيا بأنه رغبة الشاب فى تحقيق أهدافه التى تتمثل فى تكوين أسـرة

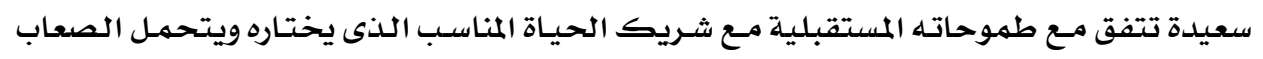

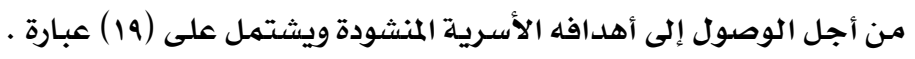

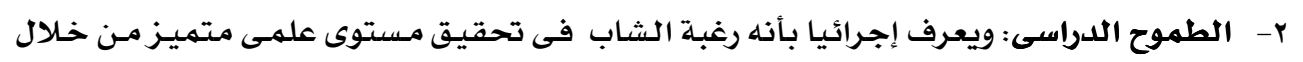

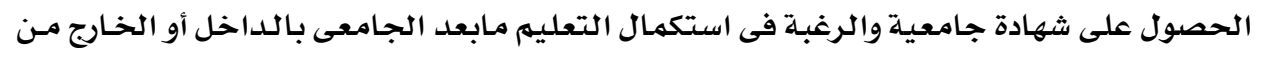


خلال التميز فى إحلدى المجالات العلمية التى درسها ومحاولة التغلب على العقبـات التى تواجههـ من أجل الوصول إلى هدفه المنشود ويشتهمل على (ع إحلى ) عبارة .

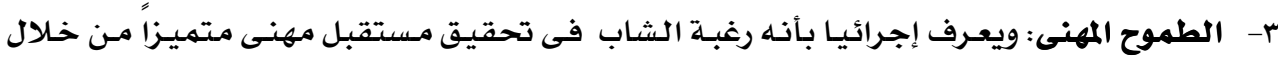

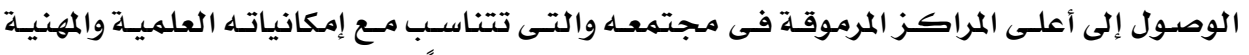

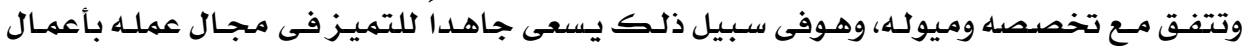

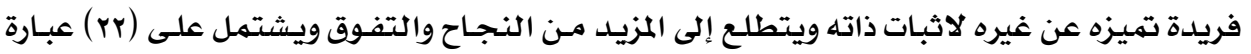

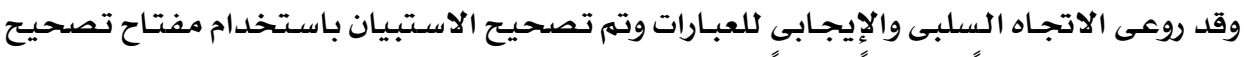

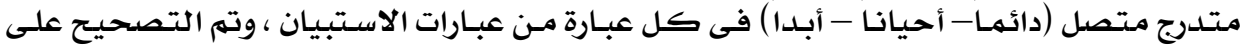

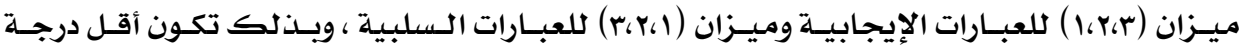

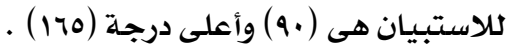

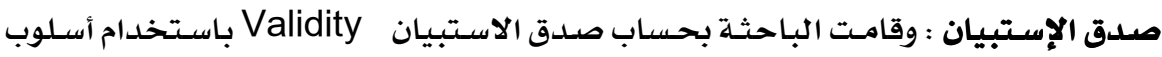

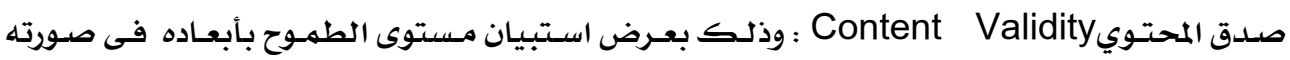

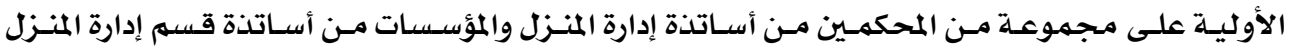

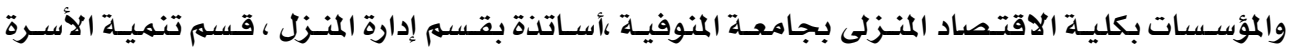

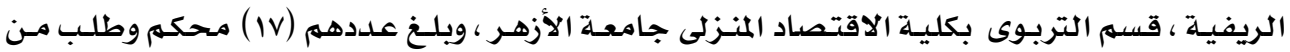

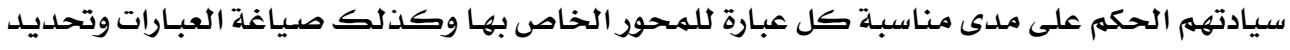

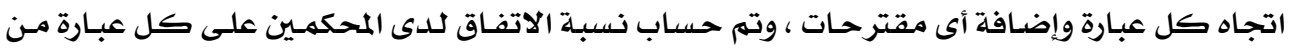

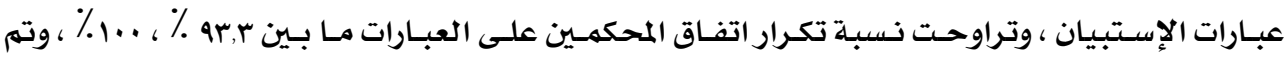

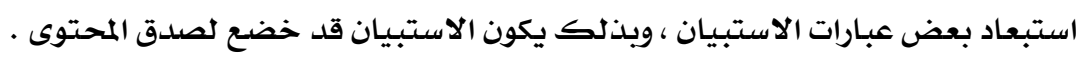
وقد تم قياس ثبات الاسـتبيان :- لحسـاب ثبـات الاستبيان تم التطبيق على عينـة قوامها

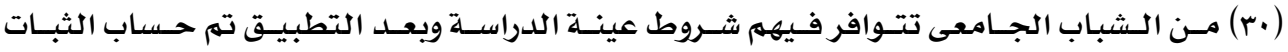

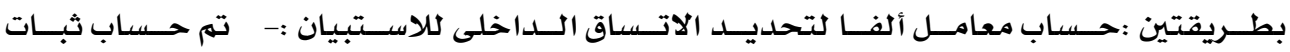

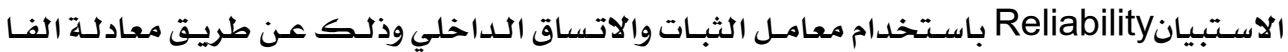

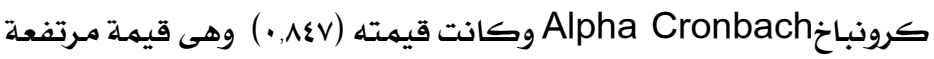

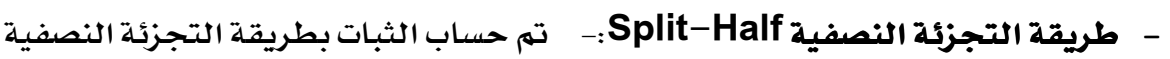

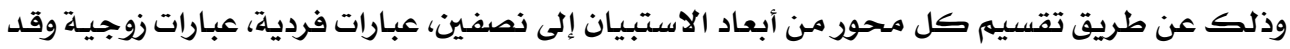

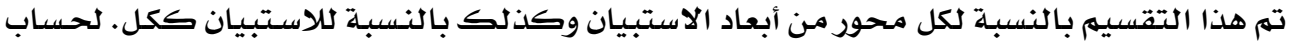

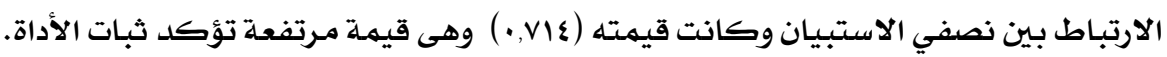

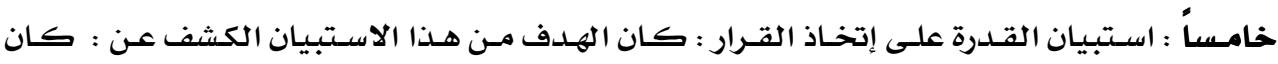

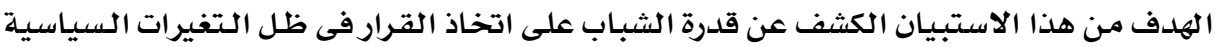

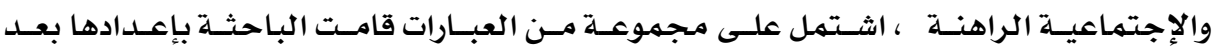


استـعراض أهـم المراجـع والدراسـات العربيـة والأجنبيـة التى تناولت موضـوع الدراسـة ، وتم إعـداد الاستبيان فى صورته الأولية

قدرة الشباب على اتخاذ القرار: ويعرف إجرائياً بأنه تمكن الشاب مـن إختيـار البـديل المتاح

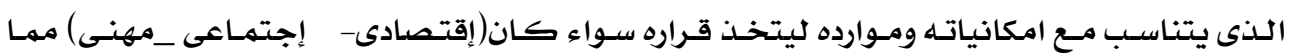

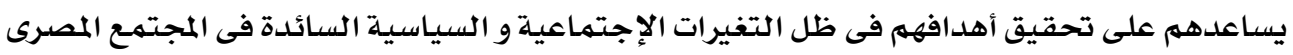

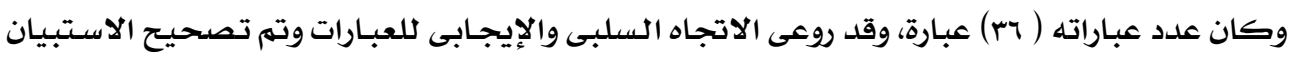

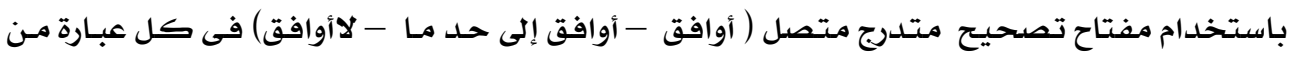

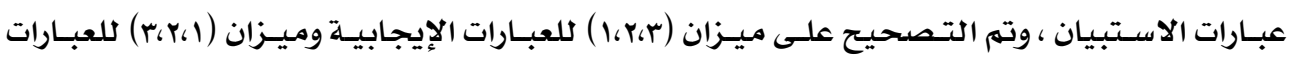

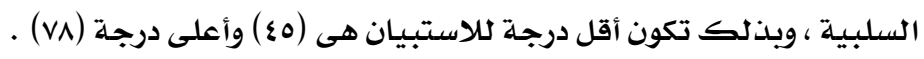

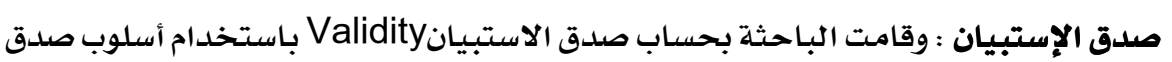

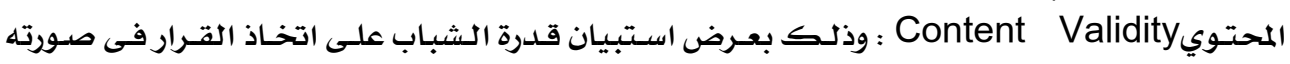

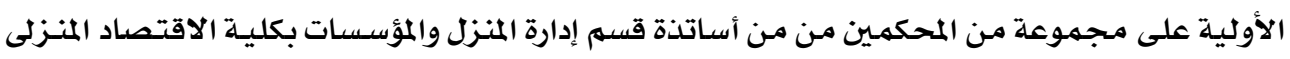

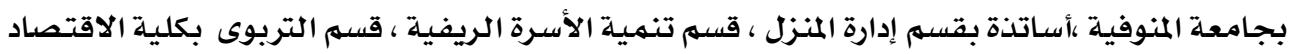

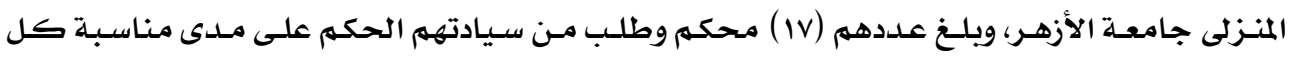

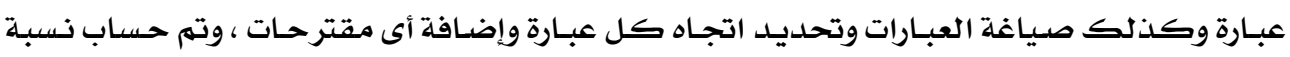

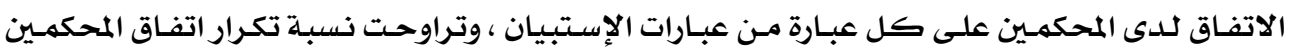

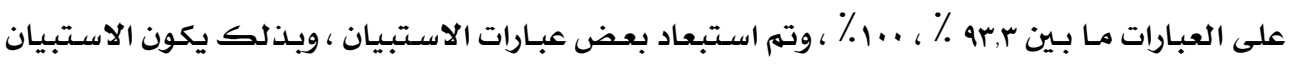

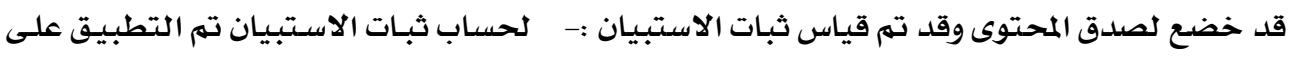

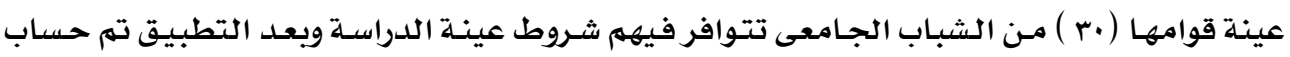

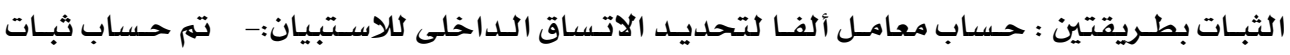

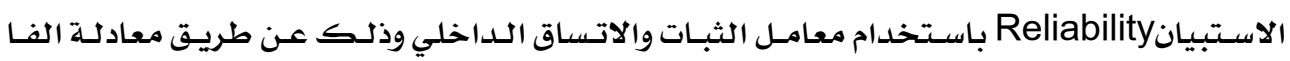

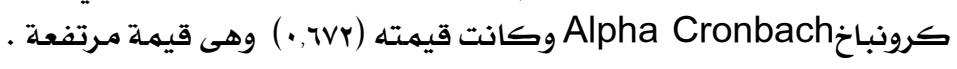

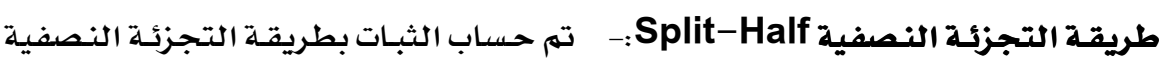

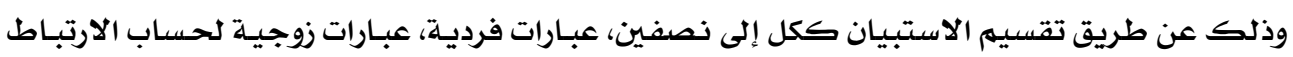

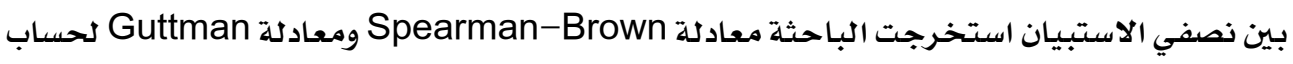

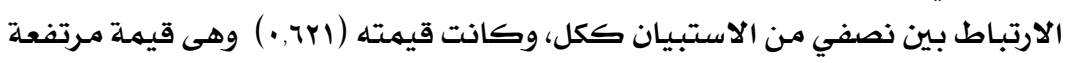

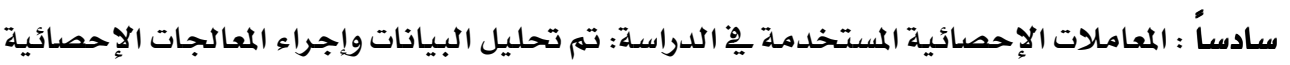

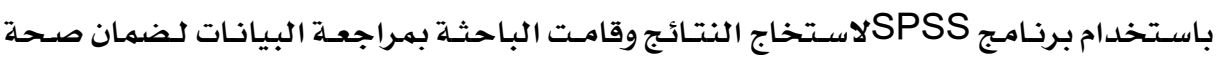

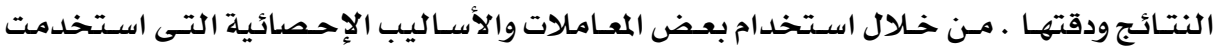

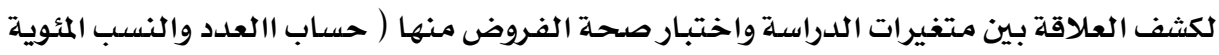

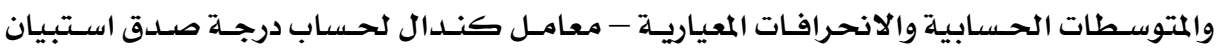

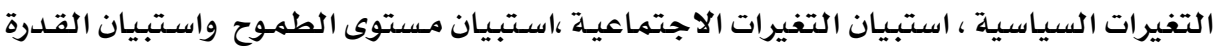




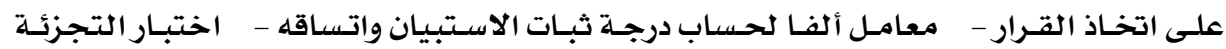

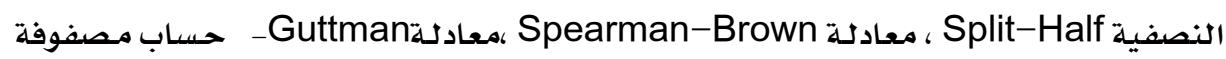

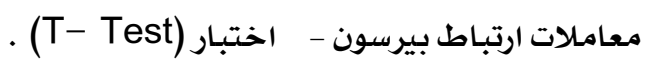

\section{نتائج الدراسة الميدانية}

أولاً: وصف عينة الدراسة :

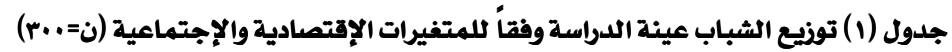

\begin{tabular}{|c|c|c|c|c|c|c|c|c|c|}
\hline$\%$ & لعدد & \multicolumn{2}{|c|}{ محل الاقامة } & $\%$ & 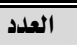 & طبيعة الدراسة & $\%$ & 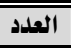 & الجنس \\
\hline 70 & $19 \xi$ & \multicolumn{2}{|c|}{ ريف } & $\pi$ & 119 & 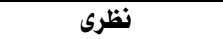 & $\xi$ & ir. & ذكور \\
\hline ro & 1.4 & \multicolumn{2}{|c|}{ حضر } & rv & III & عملى & \%. & $1 A$. & الإذاث \\
\hline 1.. & 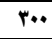 & \multicolumn{2}{|c|}{ المجموع } & 1.. & $r \cdot \cdot$ & المجموع & 1... & $r \cdots$ & المجموع \\
\hline$\%$ & لعدد & \multicolumn{2}{|c|}{ ترتيب الشاب } & $\%$ & العدد & الفرقة الدراسية & $\%$ & 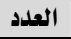 & إسم الكلية \\
\hline$v, v$ & rr & \multicolumn{2}{|c|}{ وحيد } & $r, r$ & $\eta \xi$ & الأولى - ل الأى & $r q, r$ & $\wedge \wedge$ & آداب \\
\hline$r r, r$ & 1.. & \multicolumn{2}{|c|}{ أول } & $r \cdot$ & 9. & الثانية & rq & $V \Lambda$ & تربية \\
\hline$r q, v$ & $11 \cdot$ & \multicolumn{2}{|c|}{ أوسط } & $r \wedge, r$ & 110 & الثالثة & $Y 1,7$ & 70 & إقتصاد أزهر \\
\hline$r r, r$ & vi & \multicolumn{2}{|c|}{ 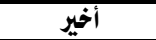 } & $1 \cdot, r$ & $\overline{1 T}$ & الرابعة - ل الرابة & $9, Y$ & $r q$ & إقتصاد عام \\
\hline 1... & $r \cdots$ & \multicolumn{2}{|c|}{ المجموع 2 - المجوع } & $1 \cdots$ & 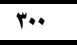 & المجموع & $7, Y$ & $r$. & شريعة \\
\hline$\%$ & لعدد & \multicolumn{2}{|c|}{ فئات اللدخل } & $\%$ & العدد & فئات علد أفرادالأسرة & 0 & 10 & تجارة \\
\hline 1\& & \&r & \multicolumn{2}{|c|}{$|\cdots\rangle$} & $r$ & 79 & صغيرة گأفراد فأقل) & $1, v$ & 0 & حقوق - حق ح ح \\
\hline rI & $\pi$ & \multicolumn{2}{|c|}{ من .... 10 10.. } & $\overline{v r}$ & r19 & متوسطة (من O_V_أفراد) & 1... & $r \cdots$ & المجموع - ل المجوع \\
\hline 14 & $0 \xi$ & \multicolumn{2}{|c|}{ من . 10>>... } & 0 & 10 & كبيرة (أكثر من V|أفراد) & & & \\
\hline$i r, r$ & $\xi$ & \multicolumn{2}{|c|}{ ro...>P...... } & 1.. & $\Gamma \cdot \cdot$ & المجموع & & & \\
\hline $1 \cdot, y$ & rY & \multicolumn{2}{|c|}{ 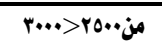 } & & & & & & \\
\hline$\overline{r T}$ & 79 & \multicolumn{2}{|c|}{$r \ldots<$} & & & & & & \\
\hline 1... & r.. & \multicolumn{2}{|c|}{ المجموع } & & & & & & \\
\hline \multicolumn{4}{|c|}{ الأم } & \multicolumn{3}{|c|}{ الأب } & \multirow{2}{*}{\multicolumn{3}{|c|}{ مستوي التعليم }} \\
\hline \multicolumn{2}{|r|}{$\%$} & \multicolumn{2}{|r|}{ العدد - م العد } & \multicolumn{2}{|c|}{$\%$} & 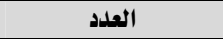 & & & \\
\hline & & & rr & \multirow[t]{3}{*}{19} & 0 & 10 & \multirow{3}{*}{ منذفض } & \multicolumn{2}{|c|}{ امي } \\
\hline & & \multicolumn{2}{|r|}{ rq } & & $9, r$ & $r A$ & & \multicolumn{2}{|c|}{ ملم بالقراءة والكتابة } \\
\hline & & \multicolumn{2}{|c|}{,$r$} & & $\{, \vee$ & $1 \xi$ & & & تعليه \\
\hline$\xi 9, r$ & & & $\%$ & $\xi 1, r$ & $14, \Gamma$ & 00 & & & \\
\hline & & & 19 & & r & 79 & متوسط & & \\
\hline & & & $7 \xi$ & & $r v, r$ & $11 \%$ & & & \\
\hline$r$ & & & $r$ & rag $y$ & $1, v$ & 0 & مرتفع & ستير & حاصل عل \\
\hline & & & 1 & & $\cdot r$ & 1 & & ت ت توراه & حاصل عل حاصل \\
\hline & & & r.. & 1... & & r.. & & & \\
\hline
\end{tabular}




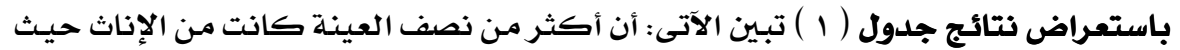

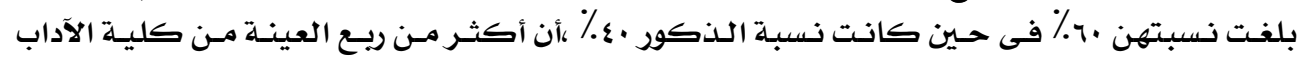

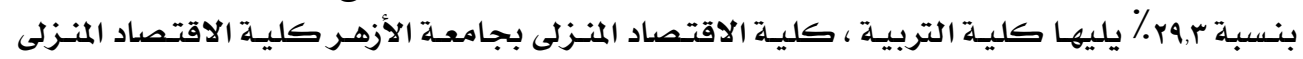

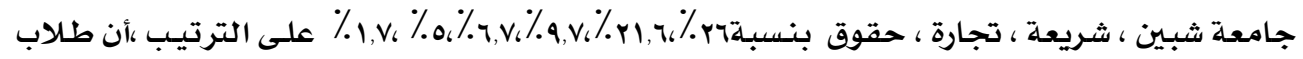

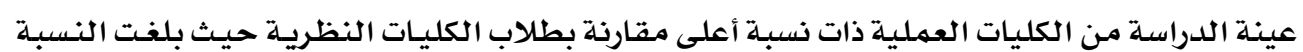

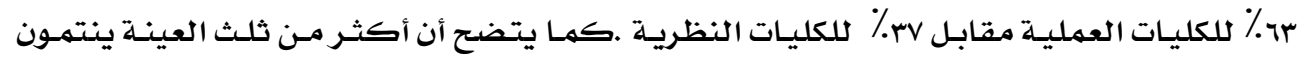

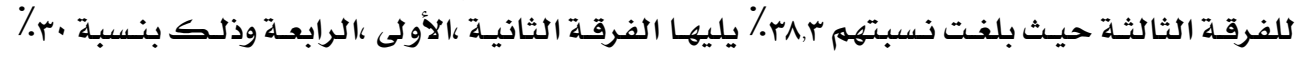

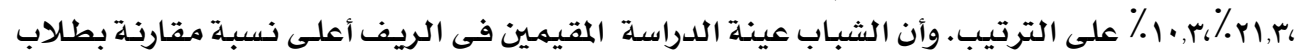

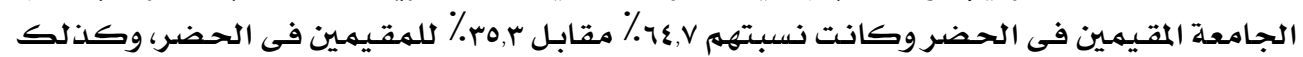

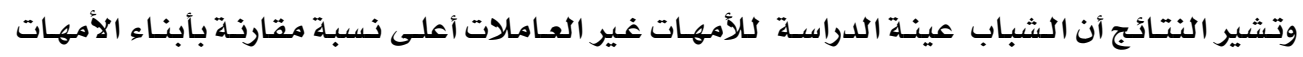

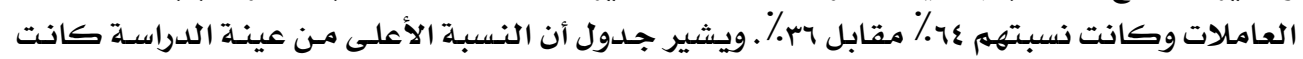

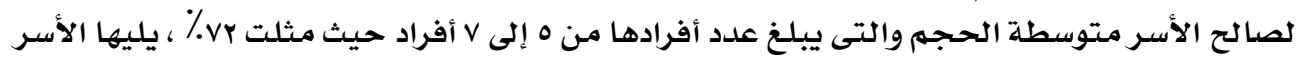

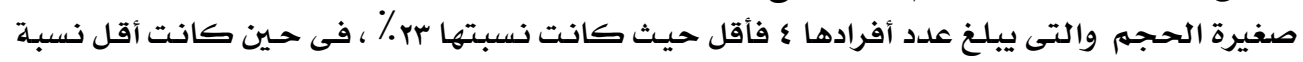

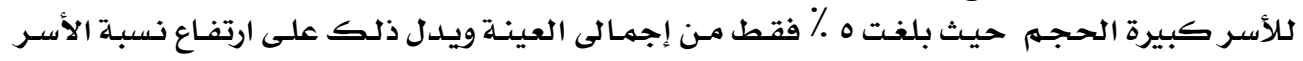

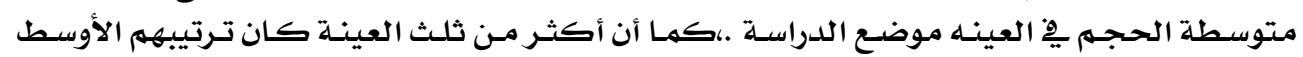

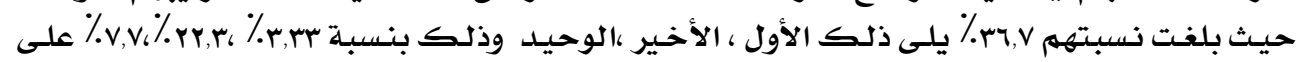

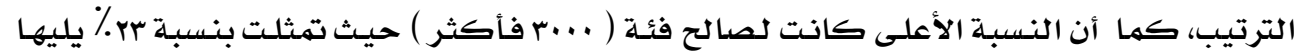

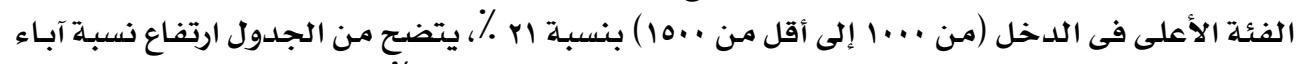

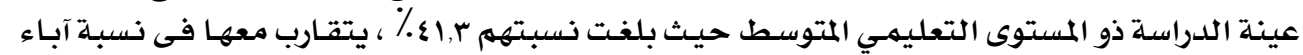

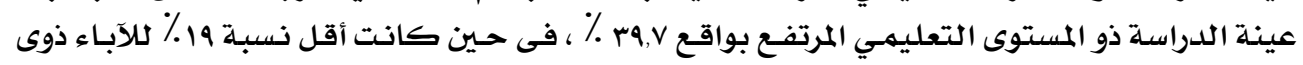

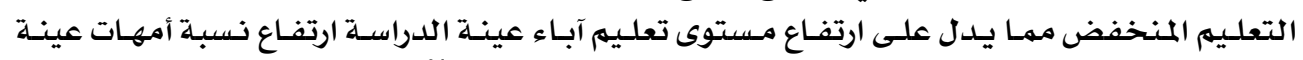

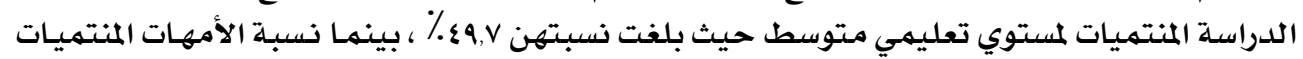

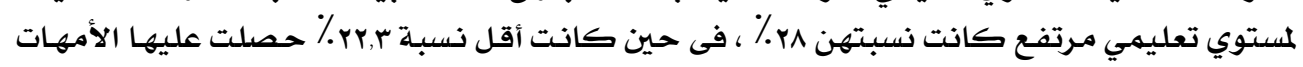

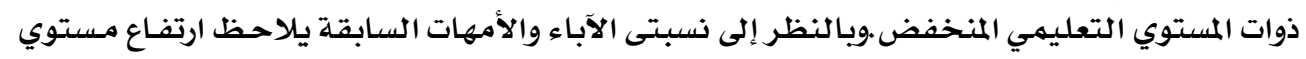

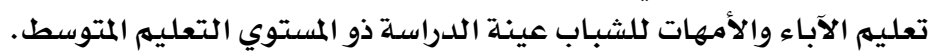
ثانياً :نتائج وصف أدوات الداء والدهات لاشياب جدول (r) التوزيع النسبى للشباب عينة الدراسة وفقاً لمستويات الإستبيان

\begin{tabular}{|c|c|c|c|c|c|c|c|}
\hline$\%$ & العدد & المستويات & البيان & $\%$ & العدد & المستويات & البيان \\
\hline 11 & r & المستوى المنخفض (•9 : إ) & \multirow{3}{*}{ الطتبيوى } & $r \cdot, r$ & 71 & 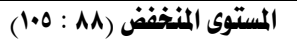 & \multirow{3}{*}{ التفبيان التيباتية } \\
\hline $\mathrm{VA}, \mathrm{V}$ & rrq & المستوى المتوسط (110 : 911) & & $\Delta \Lambda$ & IVE & المستوى المتوسط (1 1 : :YY) & \\
\hline $1 \cdot, r$ & ri & المستوى المرتفع (•1 : 190) & & $r, Y$ & 07 & المستوى المرتفع (IYY : I\&) & \\
\hline rq & AV & المستوى المنخفض (0كـ ه0) & \multirow{3}{*}{ الشتباب على الثداذ الترة } & $\xi r, r$ & ir. & المستوى المنخفض (III : V9) & \multirow{3}{*}{ الإجتمبيراتية التبيان } \\
\hline 09 & 191 & المستتوى المتوسط (79_07) & & or, r & $10 \Lambda$ & المستوى المتوسط (r|| : \&\$) & \\
\hline 10 & §० & المستوى المرتفع (VA_IV) & & $\xi$ & ir & المستوى المرتفع (IVA : IV0) & \\
\hline
\end{tabular}




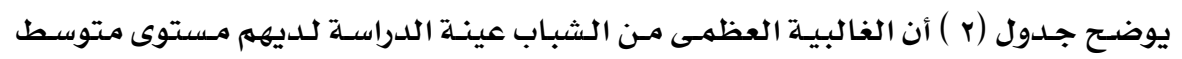

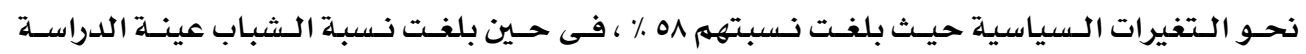

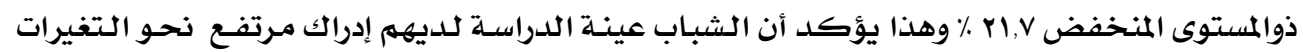

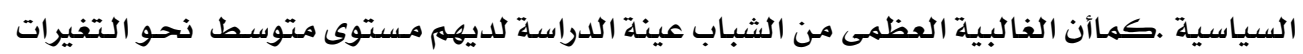

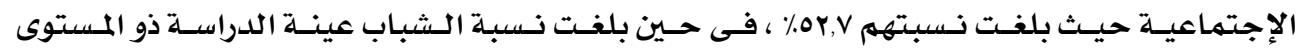

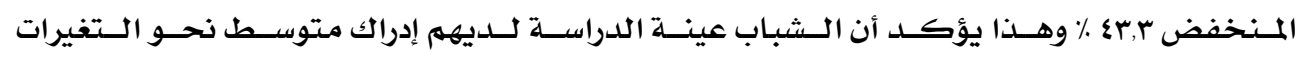

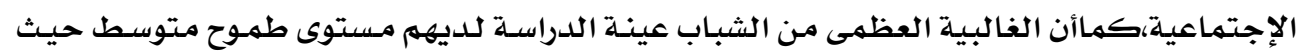

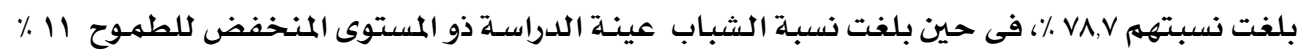

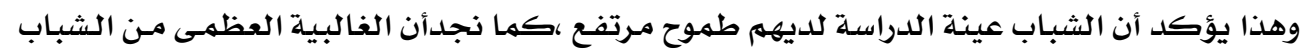

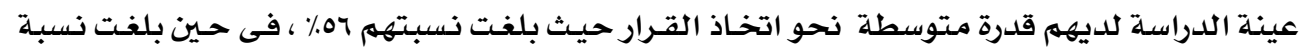

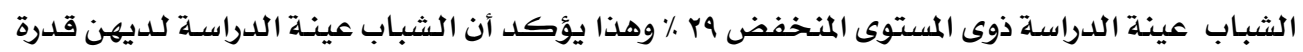
مرتفعة على اتخاذ القرار

$$
\text { النتائج فى ضوء الفروض : نتائج الفرض الأول }
$$

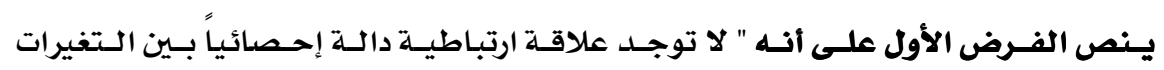

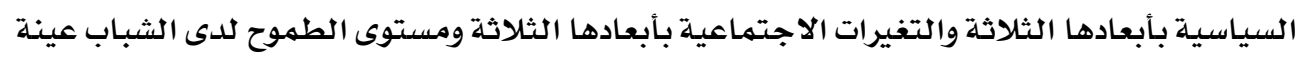
الدراسة وقدرته على اتخاذ القرار".

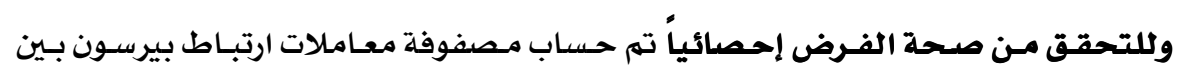

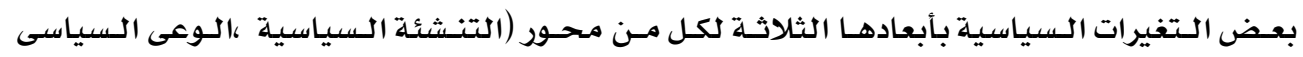

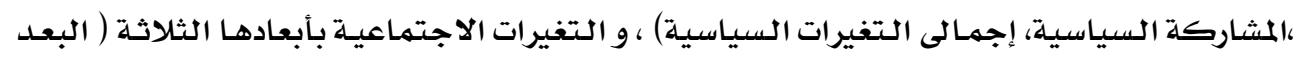

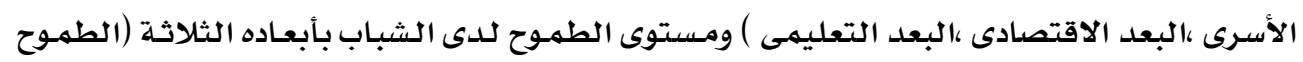

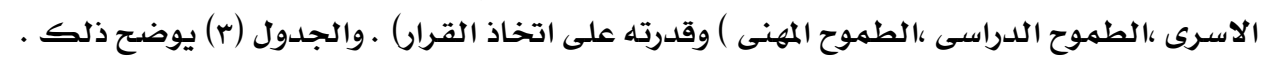


جدول (r) مصفوفة معاملات ارتباط بيرسون للتغيرات السياسية بأبعادها الثلاثة والتغيرات الاجتماعية

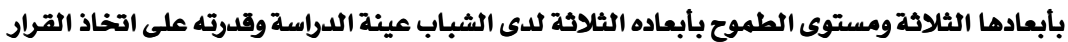

\begin{tabular}{|c|c|c|c|c|c|c|c|c|c|c|c|c|c|}
\hline الترار & إجمالى & المهنى & الطراسى & الاسرى & إجمالى & |التعليمى & |الاقتصادى |البعد & الأسرى & إجمالى & المشاركة & الوعى & التنشئة & المتفيرات \\
\hline & & & & & & & & & & & & - & السياسية \\
\hline & & & & & & & & & & & - & $* *$ *, rOA & السياسى \\
\hline & & & & & & & & & & - & $* *, \& \bullet$ & $* * \cdot r \cdot r$ & السياسية \\
\hline & & & & & & & & & - & $* *, \wedge 17$ & $* *, \quad \vee \vee$ & $* *, Y, Y, \varepsilon$ & التفيرات \\
\hline & & & & & & & & - & $* * ;, \leqslant 7$. & $* * *, \Sigma T$ T & $* *, r \wedge \uparrow$ & ***, r०६ & الأسرى \\
\hline & & & & & & & - & $* *, \Delta 94$ & $* *, r \leqslant \Lambda$ & $* *,+117$ & $\bullet, \cdot \vee \cdot$ & $*$ * Irr & |الاقتصادى \\
\hline & & & & & & - & $* *, 7 r q$ & $* *, \Delta 9 \xi$ & $* *, r v \varepsilon$ & $* *, \delta Y Y$ & ***, r rir & $* *, 150$ & التعليمى \\
\hline & & & & & - & $* *, \wedge \Delta \mathrm{V}$ & $* *, \wedge \vee \xi$ & $* * \wedge \leqslant$ & $* *, \$, \xi 17$ & $* * *, \Sigma 7 \uparrow$ & $* *, r \mid \xi$ & $* *, r \cdot \xi$ & الاجتفيراتية \\
\hline & & & & - & $\cdot, \cdot V r$ & $* *, I T V$ & •, $\cdot r_{-}$ & $\cdots 9$. & $* *, r I T$ & $* *, 109$ & •, 99 & ***, & الأسرى \\
\hline & & & - & $* *,\{r \xi$ & $* *, I V r$ & $* *, r \cdot \eta$ & $\cdot, .94$ & $* * \cdot, 101$ & $* *, \mathrm{r} M \mathrm{~F}$ & $* *$ *, rq. & $\cdot, \wedge \wedge$ & $* *, \mid A \Lambda$ & الطراسى \\
\hline & & - & **,ory & $* *, \$ 01$ & $\cdot, \Sigma 7$. & $\cdot, \cdot v 1$ & $\cdot, \cdots \Lambda_{-}$ & $* * \bullet \bullet, \vee \vee \bullet$ & $* *, 1 \wedge 0$ & ${ }^{* * * *} \bullet, 1 \leqslant 7$ & *,Irr & $*, 111$ & المهنى \\
\hline & - & $* *, \wedge \leqslant 0$ & $* *, Y \wedge r$ & $* *, \vee \vee \vee q$ & $*, 11 \%$ & $* *, 110$ & •, + Pq & $\cdot, \cdot 91$ & $* *, r Y Y$ & $* * *, r \xi Y$ & $*_{\bullet, I r \varepsilon}$ & $* *, r \mid q$ & أطمتوى \\
\hline - & $* * \cdot,\rceil \leqslant \wedge$ & $* *, 017$ & $* *,\{V Y \xi$ & $* *, 071$ & $* *, 1 \leqslant 9$ & $* *, r r q$ & •, & r & $* *, 191$ & $* *, r / 7$ & $\cdot, \cdot 0 \mathrm{r}$ & $*,|r|$ & اتخاذ القرار \\
\hline
\end{tabular}

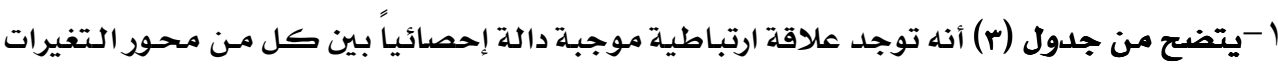

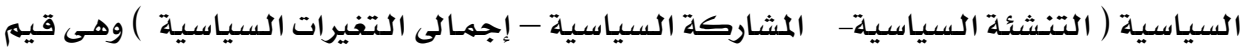

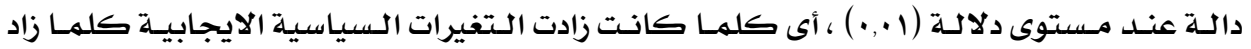

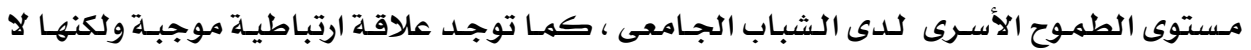

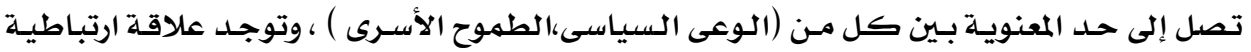

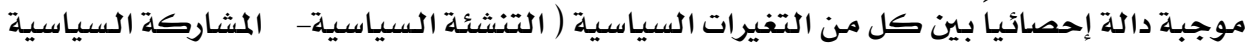

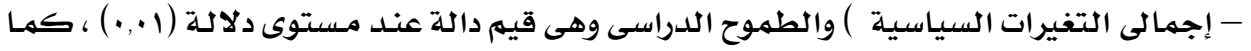

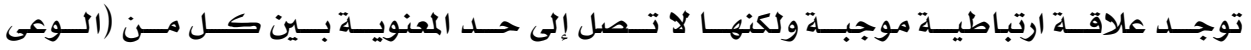

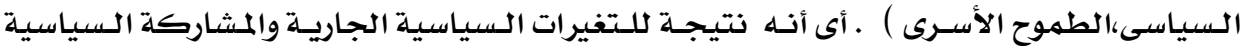

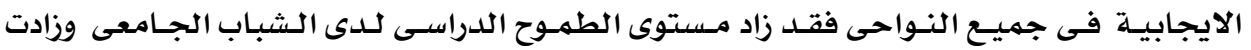

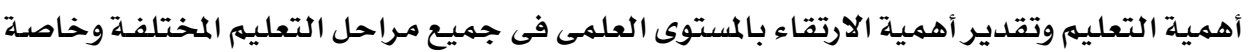


الجـامعى مـن خـلال تطبيـق الجـودة فـى العمليــة التعليميـة، إهتمام الدولـة بـالتعليم مـن خـالال

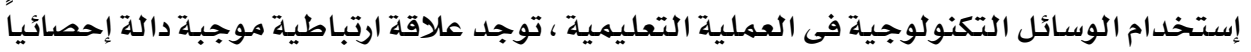

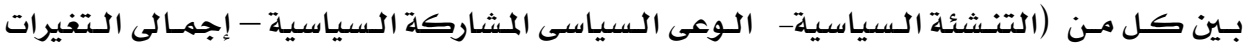

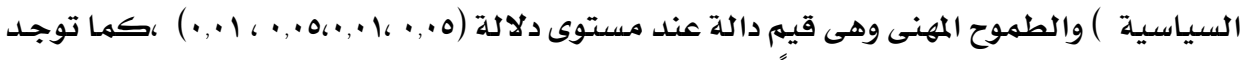

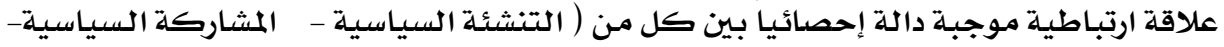

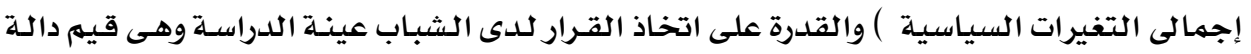

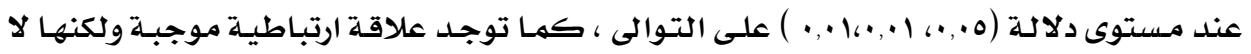

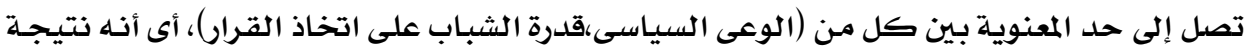

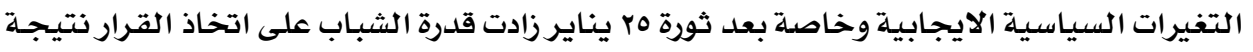

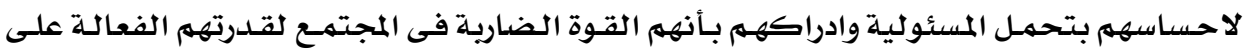

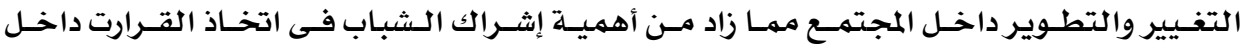
الأسـرة وخارجها التير والتهوير

كمـا توجـد علاقـة ارتباطيـة موجبـة دالـة احصـائياً بـين كل مـن البعـد التعليهى والطمهوح

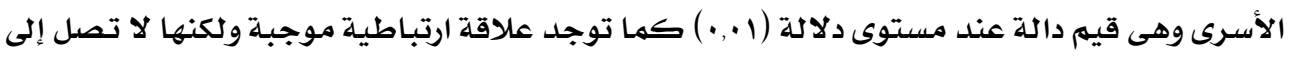

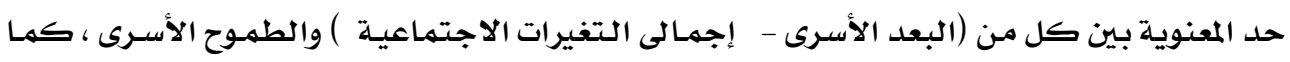

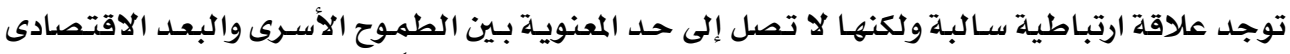

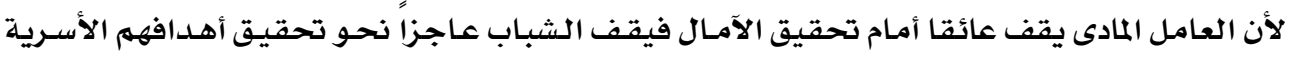

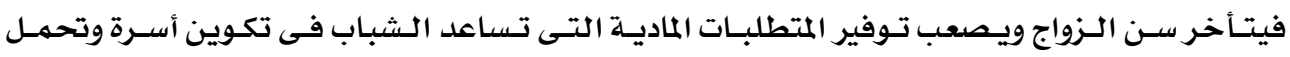

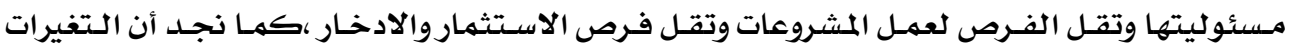

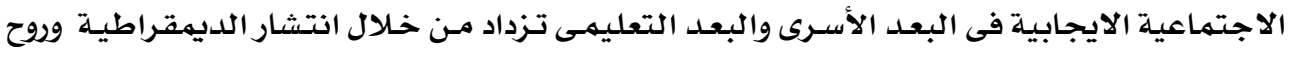

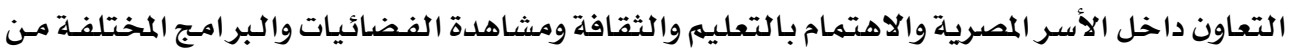

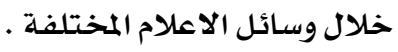

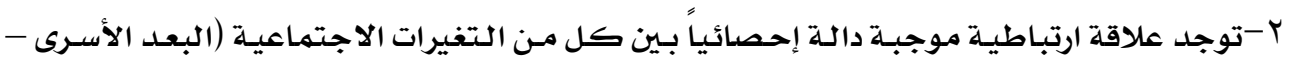

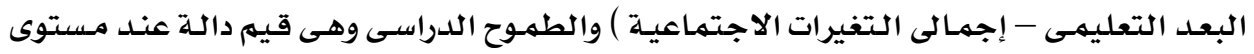

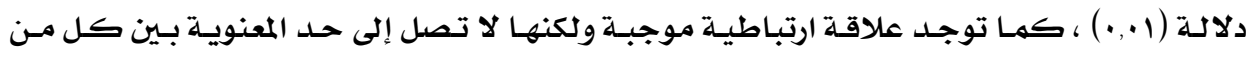

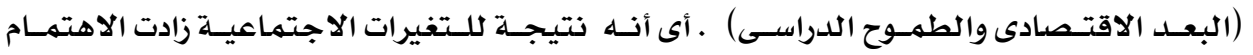

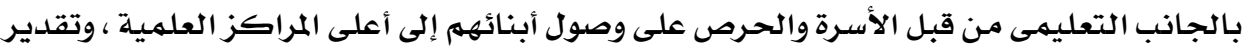

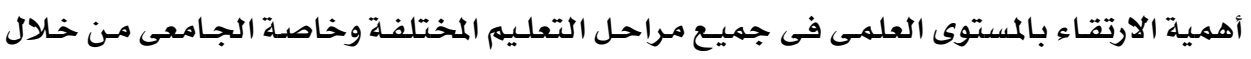

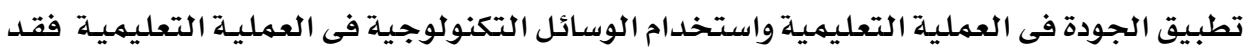

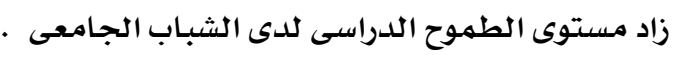

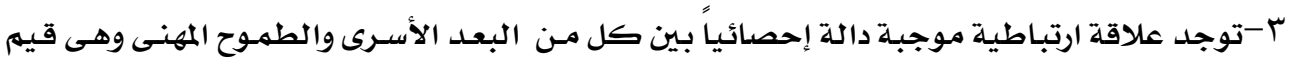

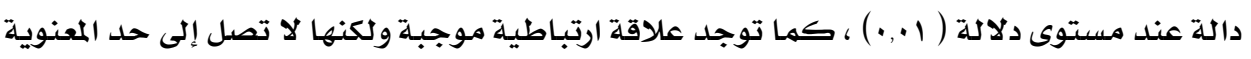


بين كل من (البعد التعليمى واجمالى التغيرات الاجتماعية والطموح المهنى ) كمها توجـد علاقـة

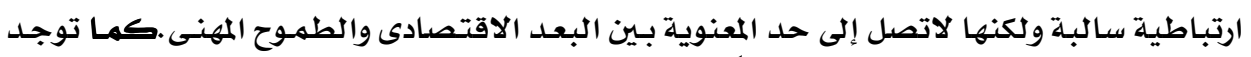

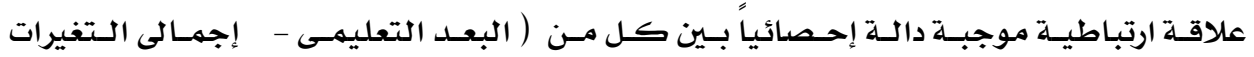

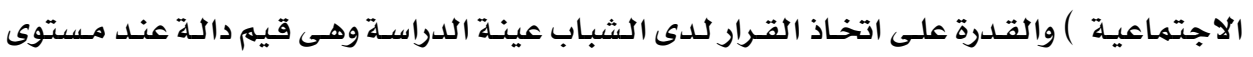

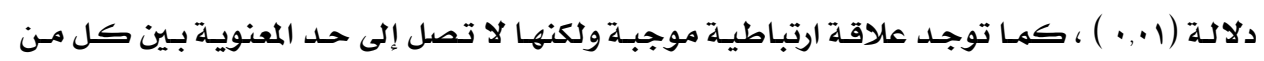

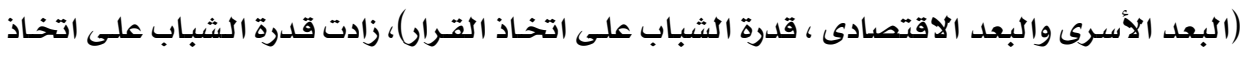

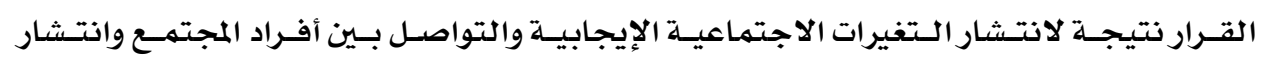

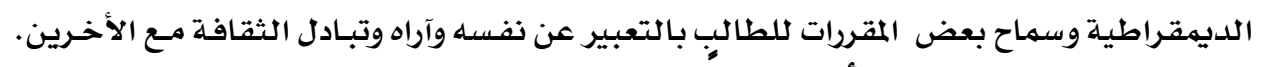

\section{وبذلك يتحقق الفرض الأول جزئياً.}

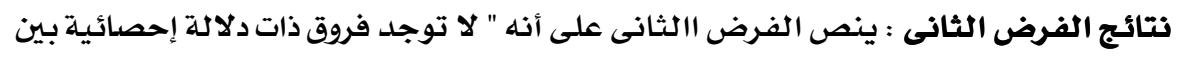

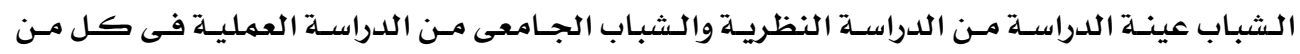

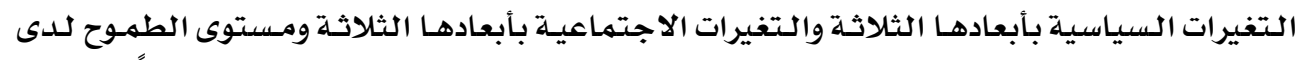

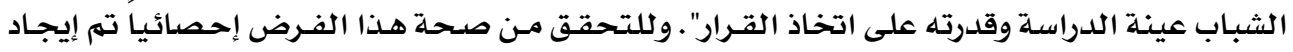

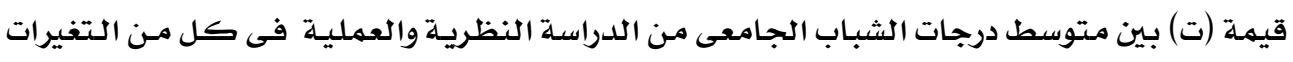

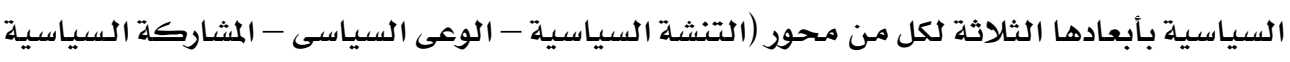

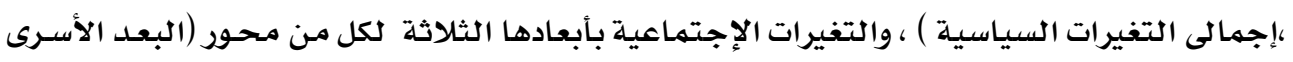

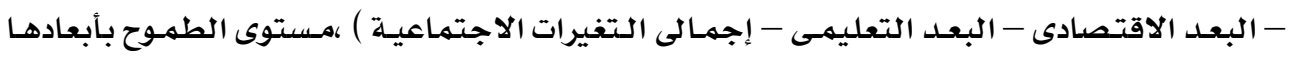

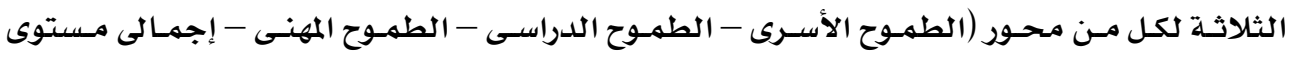

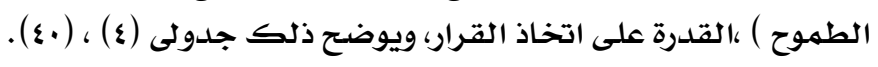

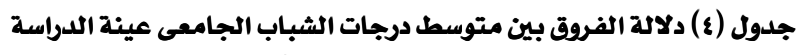

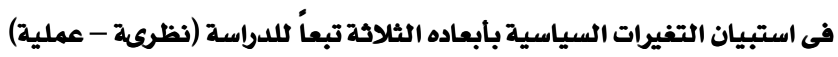

\begin{tabular}{|c|c|c|c|c|c|c|c|c|}
\hline \multirow{2}{*}{ لصالح } & \multirow[b]{2}{*}{ مستوى } & \multirow[b]{2}{*}{ قيمة } & \multirow{2}{*}{ المترسطات } & \multirow{2}{*}{ 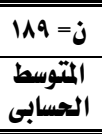 } & \multirow{2}{*}{ الحمابطي } & \multirow{2}{*}{$\begin{array}{l}\text { التحابى } \\
\text { الحسابى }\end{array}$} & \multirow{2}{*}{ التظرية } & \multirow{2}{*}{ / البيان } \\
\hline & & & & & & & & \\
\hline نظرية & 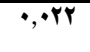 & $r, r \cdot \xi$ & 1,180 & $\$ 1$, ४৭१ & §१, Ү११ & $\{r,\{\xi \mid$ & $\{r,\{\xi 1$ & التنشة السياسية \\
\hline نظرية & $\bullet, \cdots$ & $\bar{\xi}, \wedge \xi$ & $1, \wedge \leqslant 0$ & $r q, V \cdot r$ & $r q, v \cdot r$ & $r \wedge, 0 \leqslant 9$ & $r \wedge, 0 \leqslant q$ & الوعى السياسى \\
\hline نظرية & $\cdot, \cdots$ & v, IV. & $\xi, 090$ & $r \varepsilon, 0 r q$ & r\&, orq & ra, 1ro & ra, 1 ro & السياسية \\
\hline نظرية & $\cdot, \cdots$ & $7, \& \cdot 0$ & $\checkmark, 017$ & $11 \%$, ora & lir,orq & $1 r \cdot, 1 r q$ & $1 r \cdot, 1 r q$ & إجمالي استيبيان \\
\hline
\end{tabular}

يتبين من جدول (ع) أنه توجد فروق ذات دلالة إحصائية بين الشباب الجامعى عينة الدراسة

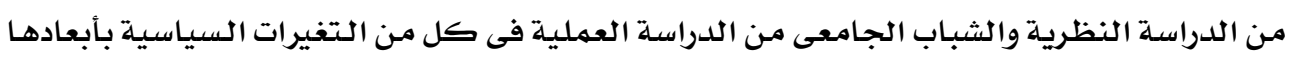

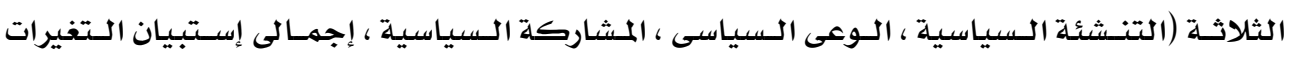




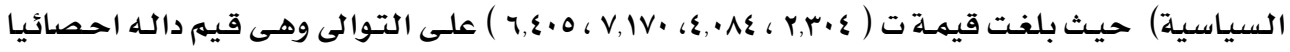

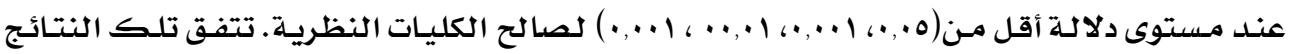

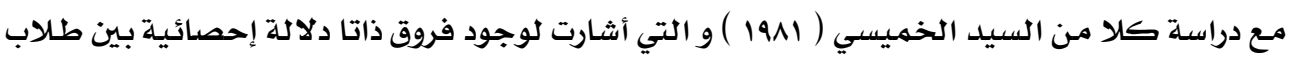

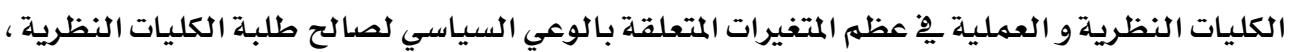

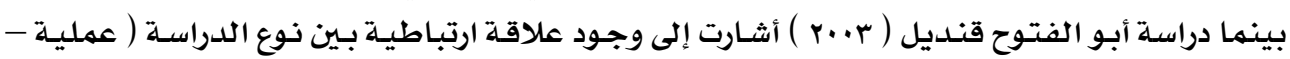

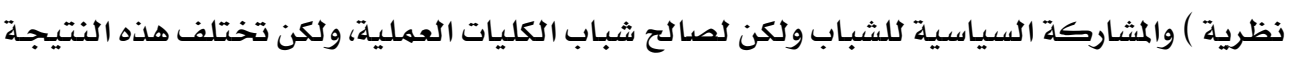

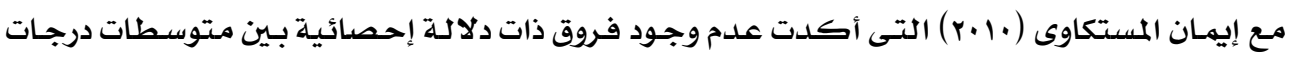

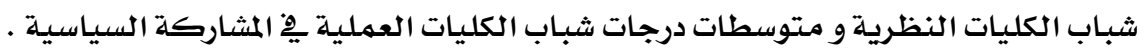

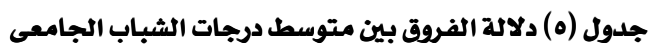

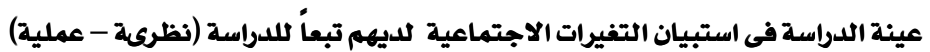

\begin{tabular}{|c|c|c|c|c|c|c|c|c|}
\hline \multirow{2}{*}{ لصالح اللالة } & \multirow{2}{*}{ مستوى الدلالة } & \multirow{2}{*}{ قيمة } & \multirow{2}{*}{ المترسطات بين } & $119=j$ & عملية & $\mid I I=\dot{j}$ & نظرية & \\
\hline & & & & الحسابى التوسط & الحسابى التوسط & الحسوسط & الحستوسط & \\
\hline نظرية & $\bullet, \cdots$ & $\xi$, YqY & $r, \cdot 7 \Lambda$ & 0, ATS & rq, rYA & 7,191 & \&Y, rq৭ & البعد الأسرى \\
\hline نظرية & $\bullet, \cdot \bullet r$ & r,IVr & $r, 7770$ & $v, r+q$ & ro, $7 ו r$ & $7, O Y 1$ & rA, rVq & البعد الاقتصادى \\
\hline نظرية & $\cdot, \cdot \bullet Y$ & $r, I V V$ & r, rOA & $0, \mathrm{YOI}$ & $r v, \bullet \xi V$ & I,rYr & $r q, r \cdot q r$ & البعد التعليمى \\
\hline نظرية & $\cdot, \cdot \bullet$ & $\xi, Y \cdot Y$ & $\Lambda, Y r \cdot$ & $17, \leqslant 7 \%$ & $11 \xi, 90$ & $17,1 V \varepsilon$ & Irr, rior & التفرات الاجمالى استيبيانية \\
\hline
\end{tabular}

يتضع من جدول (ه) مايلى :أنه توجد فروق ذات دلالة إحصائية بين الشباب الجامعى عينسة

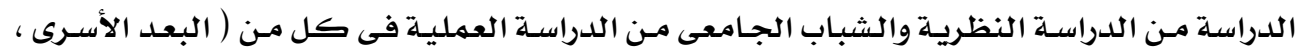

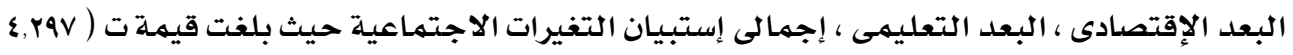

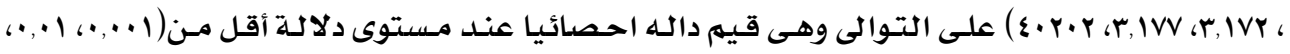

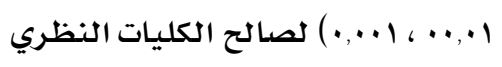

جدول (ج) دلالة الفروق بين متوسط درجات الشباب الجامعى الشئ

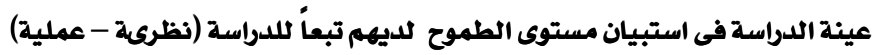

\begin{tabular}{|c|c|c|c|c|c|c|c|c|}
\hline \multirow{2}{*}{ الصالح } & \multirow[b]{2}{*}{ مستوى } & \multirow[b]{2}{*}{ قيمة ت } & \multirow{2}{*}{ المترقطات } & $1 \wedge q=j$ & عملية & j & نظرية & \\
\hline & & & & الحسابى & الحسوسط & الحسابي & الحسوسط & \\
\hline نظرية & $\cdot, \cdot 0$ & 1,970 & $1, \cdot r \Lambda$ & $\xi, \cdot Y Y$ & \&Y,AYY & $\xi, 9 Y 0$ & $\{r, \wedge\rceil \xi$ & الطموح الأسرى \\
\hline نظرية & •,יץr & $r, 1 \leqslant 9$ & $1,8 \cdot 9$ & r,orl & $\gamma 1,7 \cdot 1$ & $\xi, \cdot \vee \wedge$ & Rr, & الطراسى \\
\hline نظرية & $\cdot,+r \Lambda$ & $r, r+1$ & $1, \mathrm{rar}$ & $\xi, \wedge \uparrow\}$ & $0 .,\{\wedge\rceil$ & $0, \cdot 40$ & OI,YAY & الطهوح المهنى \\
\hline نظرية & $\bullet$ & r, १9. & r, Yro & 1., & $|r \xi, q F|$ & $1 \cdot, 974$ & $17 \alpha, 774$ & مستوى الطموح استبيان \\
\hline
\end{tabular}


يتضح من جدول (ج) مايلى : توجد فروق ذات دلالة إحصائية بين متوسطات درجـات الشباب

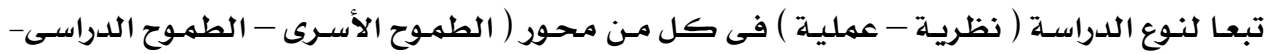

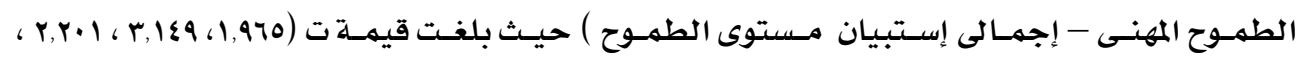

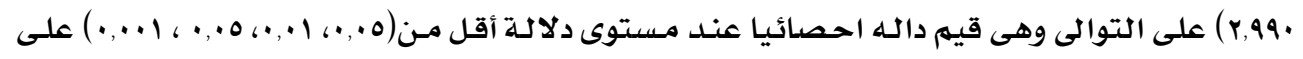

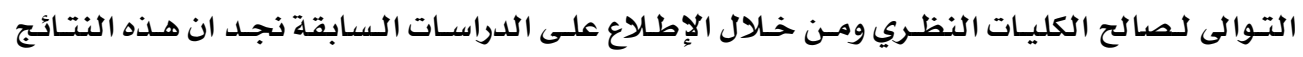

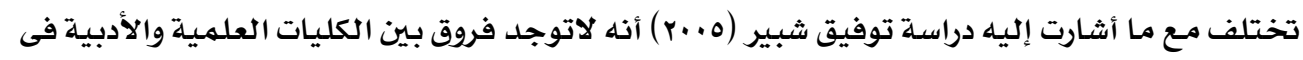

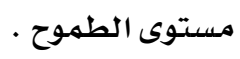

جدول (v) دلالة الفروق بين متوسط درجات الشباب الجامعى الفيان

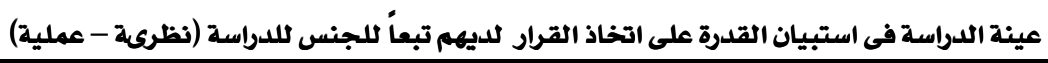

\begin{tabular}{|c|c|c|c|c|c|c|c|}
\hline \multirow[b]{2}{*}{ مستوى اللدلالة } & \multirow[b]{2}{*}{ قيمة } & \multirow[b]{2}{*}{ المتوسطاتي } & \multicolumn{2}{|c|}{ عملية = 1199 } & \multicolumn{2}{|c|}{ نظرية ذ=|III } & \\
\hline & & & الالميارى & الحتوسط & الالميارى & الحسابى & \\
\hline 19 ,•(غيردالة) & $1, r 11$ & 1, r ror & 7, rYY & $09,1 Y Y$ & $r, 0 . r$ & $7 \cdot, 17 r$ & إجمالى استخبيان القدارة \\
\hline
\end{tabular}

يتضح من جدول (v) : عدم وجود فروق بـين متوسطات درجـات الشباب مـن الذكور والإناث

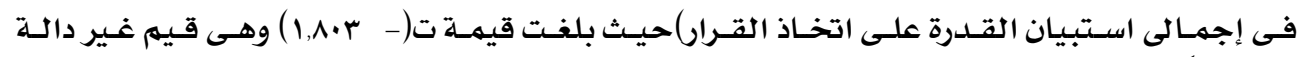

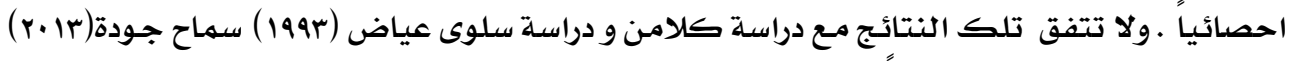

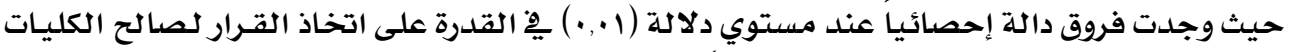
العملية وبذلك يتحقق الفرض الثانى جزئياً. رابعاً : توصيات الدراسة : فى ضوء ما أسفرت عنه نتائج الدراسـة :

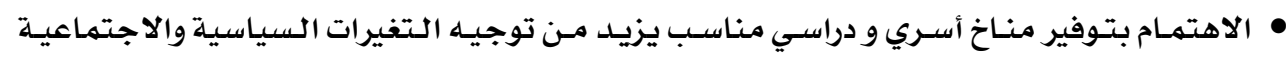

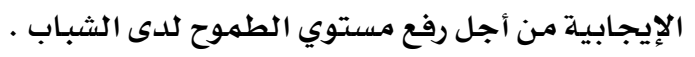

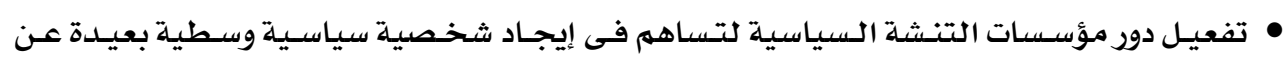
التطرف الذى يضر بالمجتهمع.

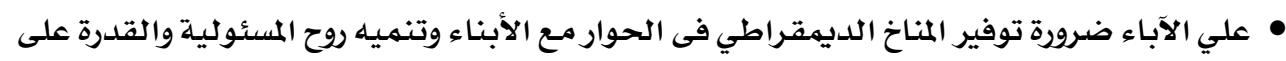

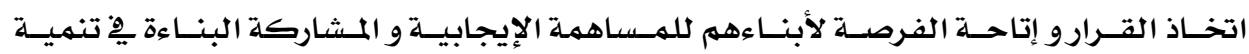

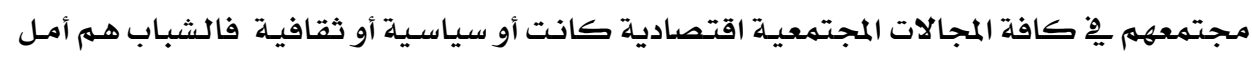

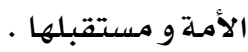
• إعادة صياغة فلسفة التعليهم الجـامعي و أهدافه بهـا يتلاءم مـع التطورات السياسية والاقتصادية والاجتماعية 


\section{قائمة المراجع}

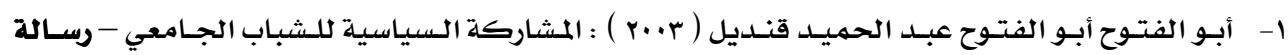

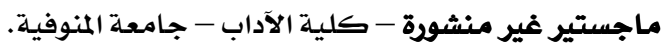

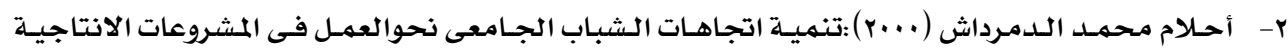

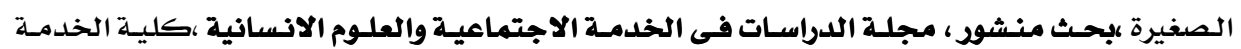

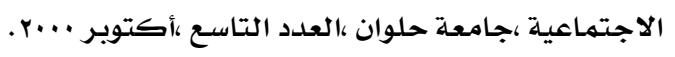

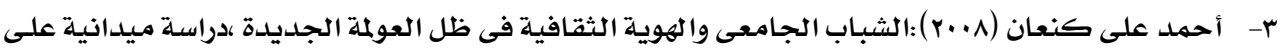

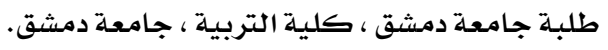

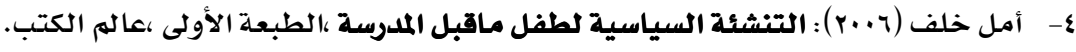

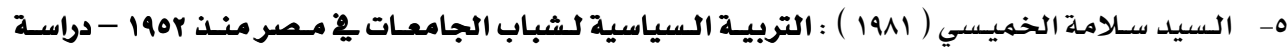

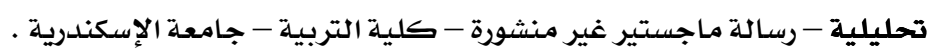

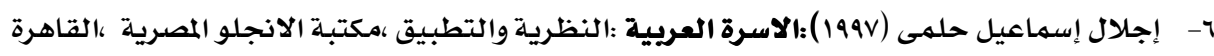

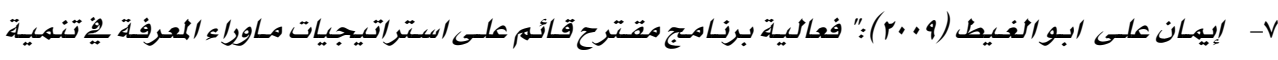

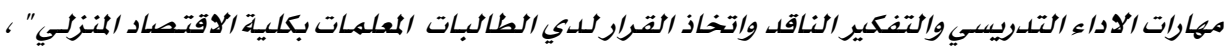

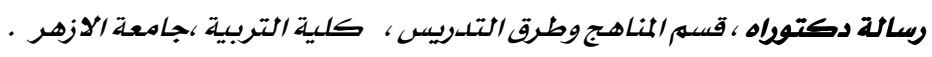

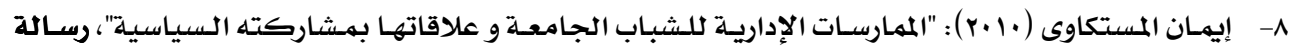

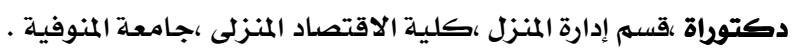

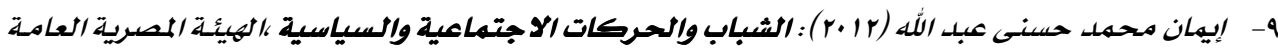

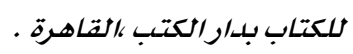

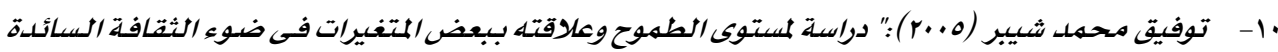

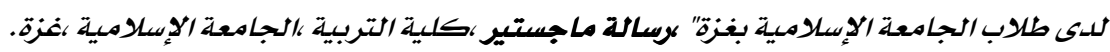

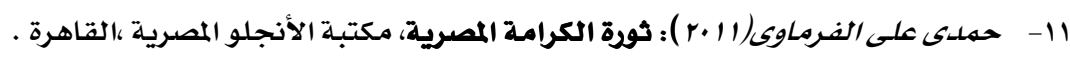

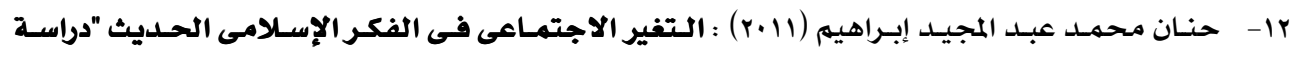

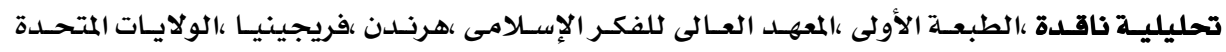

$$
\text { الأمريكية. }
$$

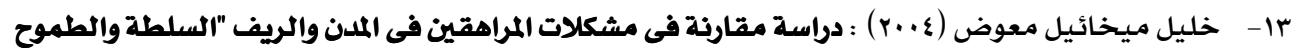

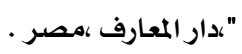

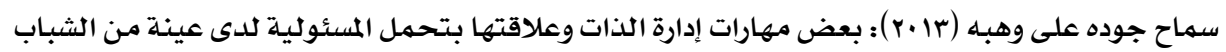
$-18$

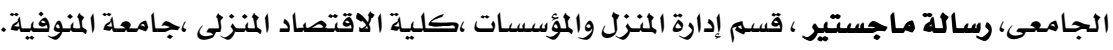

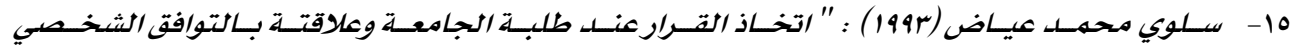

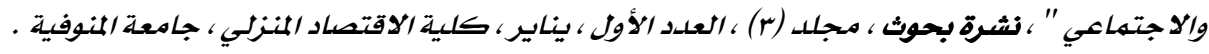

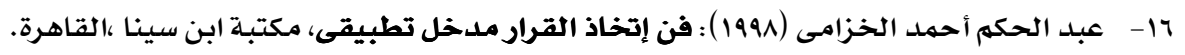




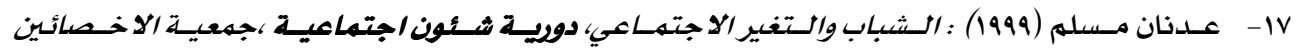

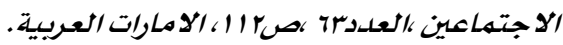

11- عزت حجازي(1910): الثباب العربي ومشكلاته، عالم المعرفة، العدد (ج)، المجلس الوطني للثقافة و الفنون والآداب ،الكويت .

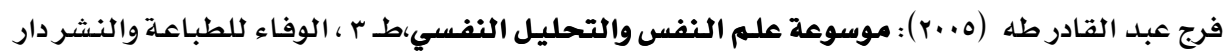
السعاد الصباح، أسيوط

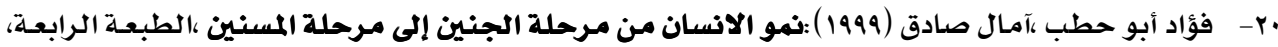
مكتبة الأنجلو المصرية

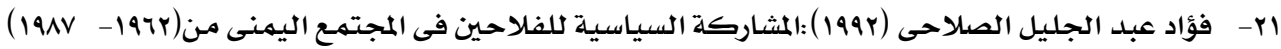
، رسالة ماجستير ،كلية الآداب ،جامعة عين شمس.

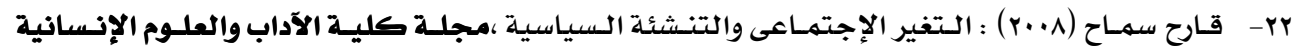

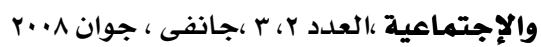

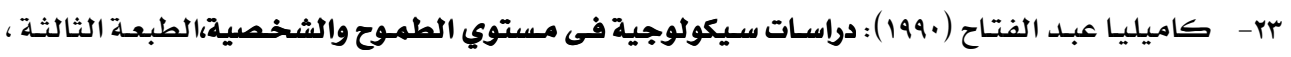
دارنهضة مصر، الفجالة ، القاهرة.

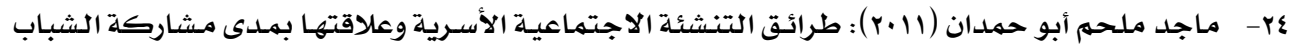

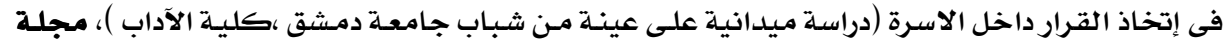

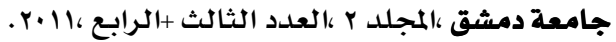

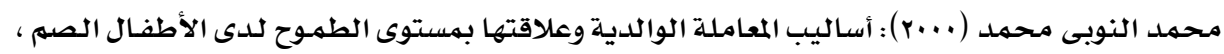

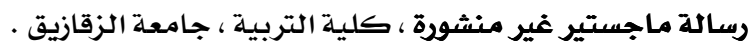

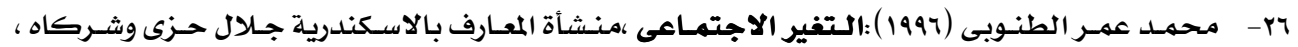
جامعة الاسكندرية ج مع ،جامعة عمر المختار ليبيا .

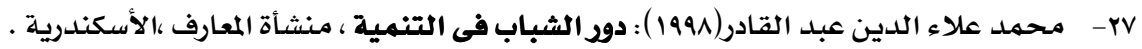

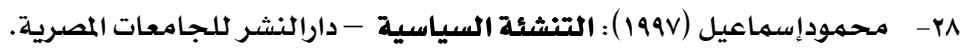

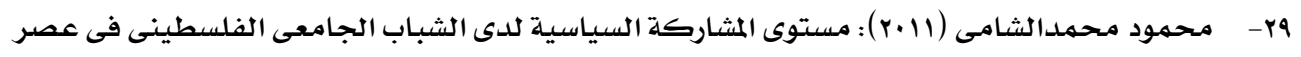

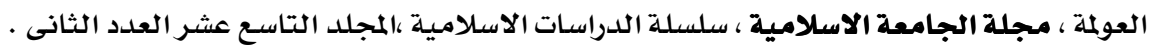

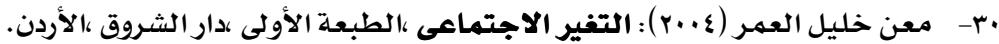

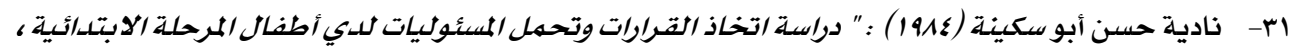

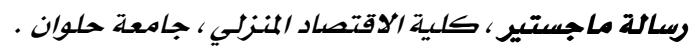

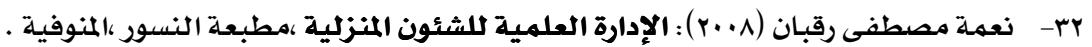
Harton Persona(2005): Youth and proplem of change (New York: Osaka puplisherm, 
Political and social changes and their relationship to the level of ambition among the youth and his ability to take decision

Prepared by

Prof. Dr. Neama Mostafa Rakaban

Dr. Mona Moostafa EL.Zaki Mohammed

the researcher / Shaimaa Moustafa Moustafa Elzeky

\section{Abstract}

The aim of the present study was to identify the relationship between the political and social changes and the level of ambition among young people and its ability to decision-making

\section{The study was conducted on:}

300 students in university education, the researcher used the search tool, which consisted of initial data form student of the university, a questionnaire political changes, social changes and a questionnaire, a questionnaire and the level of ambition, and a questionnaire on the ability of young people to take the decision.

\section{: The most important findings of the study}

1- There is a positive correlation statistically significant between each of the axis of political changes and the level of ambition.

2-There were statistically significant differences between male and female university students study sample in each of the axis of each of the questionnaire social changes in favor of males.

3- There is a statistically significant variation among young university study sample in the social changes depending on the school band for the second year.

\section{Recommendations of the study:}

-activate the role of political institutions Altench to contribute to finding a political figure and the average is far from extremism, which harms society.

- provide an opportunity for young people to express themselves through the allocation of seats in the People's Assembly and the Shura Council of the young.

- urged various media, especially the visual interest in the work programs. 